\title{
Neonicotinoid Seed Treatments Have Significant Non-target Effects on Phyllosphere and Soil Bacterial Communities
}

OPEN ACCESS

Edited by:

Yurong Liu,

Huazhong Agricultural University,

China

Reviewed by:

Yijun Dai,

Nanjing Normal University, China Yitzhak Hadar,

Hebrew University of Jerusalem, Israel

*Correspondence:

Steven W. Kembel

kembel.steven_w@uqam.ca

Benjamin Mimee

benjamin.mimee@canada.ca

Specialty section:

This article was submitted to Terrestrial Microbiology, a section of the journal

Frontiers in Microbiology

Received: 21 October 2020

Accepted: 14 December 2020

Published: 13 January 2021

Citation:

Parizadeh M, Mimee B and Kembel SW (2021) Neonicotinoid Seed Treatments Have Significant Non-target Effects on Phyllosphere and Soil Bacterial Communities.

Front. Microbiol. 11:619827. doi: 10.3389/fmicb.2020.619827

\author{
Mona Parizadeh ${ }^{1,2}$, Benjamin Mimee ${ }^{1 *}$ and Steven W. Kembel ${ }^{2 *}$ \\ ${ }^{1}$ Agriculture and Agri-Food Canada, Saint-Jean-sur-Richelieu, Quebec, QC, Canada, ${ }^{2}$ Département des sciences \\ biologiques, Université du Québec à Montréal, Montréal, QC, Canada
}

The phyllosphere and soil are dynamic habitats for microbial communities. Nonpathogenic microbiota, including leaf and soil beneficial bacteria, plays a crucial role in plant growth and health, as well as in soil fertility and organic matter production. In sustainable agriculture, it is important to understand the composition of these bacterial communities, their changes in response to disturbances, and their resilience to agricultural practices. Widespread pesticide application may have had non-target impacts on these beneficial microorganisms. Neonicotinoids are a family of systemic insecticides being vastly used to control soil and foliar pests in recent decades. A few studies have demonstrated the long-term and non-target effects of neonicotinoids on agroecosystem microbiota, but the generality of these findings remains unclear. In this study, we used 16S rRNA gene amplicon sequencing to characterize the effects of neonicotinoid seed treatment on soil and phyllosphere bacterial community diversity, composition and temporal dynamics in a 3-year soybean/corn rotation in Quebec, Canada. We found that habitat, host species and time are stronger drivers of variation in bacterial composition than neonicotinoid application. They, respectively, explained $37.3,3.2$, and $2.9 \%$ of the community variation. However, neonicotinoids did have an impact on bacterial community structure, especially on the taxonomic composition of soil communities (2.6\%) and over time (2.4\%). They also caused a decrease in soil alpha diversity in the middle of the growing season. While the neonicotinoid treatment favored some bacterial genera known as neonicotinoid biodegraders, there was a decline in the relative abundance of some potentially beneficial soil bacteria in response to the pesticide application. Some of these bacteria, such as the plant growthpromoting rhizobacteria and the bacteria involved in the nitrogen cycle, are vital for plant growth and improve soil fertility. Overall, our results indicate that neonicotinoids have non-target effects on phyllosphere and soil bacterial communities in a soybeancorn agroecosystem. Exploring the interactions among bacteria and other organisms, as well as the bacterial functional responses to the pesticide treatment, may enhance our understanding of these non-target effects and help us adapt agricultural practices to control these impacts.

Keywords: bacterial community structure, bacterial diversity, host-microbe interactions, neonicotinoid seed treatment, pesticide non-target effects, phyllosphere, soil bacterial communities, temporal variation 


\section{INTRODUCTION}

The phyllosphere (the aerial surfaces of plants including leaves) and soil are colonized by microbial communities (microbiota), which are of great importance in the regulation of host and ecosystem function. These microbial communities, including beneficial bacteria, play a crucial role in plant growth promotion, decomposition and health control (Vorholt, 2012), as well as in soil fertility, nitrogen fixation, and organic matter production (Doran and Zeiss, 2000; Garbeva et al., 2004). Previous studies have shown that the taxonomic composition of phyllosphere bacteria is associated with host plant species identity (Whipps et al., 2008; Knief et al., 2010; Kembel et al., 2014) and changes predictably during the growing season and as plant ages (Redford and Fierer, 2009; Sugiyama et al., 2014; Wagner et al., 2016). Host species were found to be a more important driver of variation in phyllosphere bacterial communities than time (Laforest-Lapointe et al., 2016b). Other studies on the composition of soil bacteria have associated community variations with host plant species and growth stage (Wieland et al., 2001), site (Clairmont et al., 2019) and time (Tarlera et al., 2008; Hannula et al., 2019). Host species were also shown to be a stronger driver of variation in soil bacterial communities than host plant growth stage and development time (Wieland et al., 2001).

Bacterial succession refers to the bacterial community variation patterns over time and in response to environmental changes and disturbances (Redford and Fierer, 2009). Comparing temporal versus spatial variation in bacterial community structure, the effects of time (seasonal variability) on bacterial communities is often higher than habitat impacts (Samaritani et al., 2017). Environmental disturbances and perturbations (such as cultivation methods, drought, climate change, and pesticide treatments) can also alter the bacterial community structure and composition (Schimel et al., 2007; Itoh et al., 2014). During the succession process, some bacterial communities may survive by modifying their habitat, increasing their abundance or becoming more resistant or resilient to disturbances (Schimel et al., 2007; Fierer et al., 2010). Hence, if a disturbance is persistent, it can cause long-term changes in bacterial community structure and affect bacterial succession (Fierer et al., 2010). During the last decades, the widespread application of chemical pesticides in agro-ecosystems has influenced many non-target species and their succession patterns (Itoh et al., 2014; RodríguezValdecantos et al., 2017). Pesticides can change the interaction between plants and some bacteria, such as nitrogen-fixing rhizobacteria, which may lead to the inhibition of nitrogen fixation (Fox et al., 2007; Lo, 2010). They can also affect soil fertility and quality by impacting soil bacterial diversity and function and altering their nitrification, denitrification and mineralization of organic matter (Hussain et al., 2009). In this study, to assess the effects of pesticides on the phyllosphere and soil bacterial community structure and intra- and inter-annual

Abbreviations: ANOVA, Analysis of variance; ASV, Amplicon sequence variant; DESeq2, Differential expression analysis of sequence data; FDR, False-discovery rate; NMDS, Non-metric multidimensional scaling; NST, Neonicotinoid seed treatment; PCoA, Principal coordinate analysis; PERMANOVA, Permutational analysis of variance; SE, Standard error. succession, we have focused on a class of the most widely used insecticide pesticides, neonicotinoids.

Neonicotinoids (also known as neonics) are a family of systemic and neuro-active insecticides, chemically similar to nicotine, introduced in the late 1980s (Kagabu, 1996; Tomizawa and Casida, 2005). Like nicotine, they interrupt neural transmission in the nervous system by binding to the nicotinic acetylcholine receptors (nAChRs). Because of the fundamental distinctions between the nAChRs of invertebrates and vertebrates, neonicotinoids are selectively more toxic to invertebrates, like insects (Tomizawa et al., 1999; Tomizawa and Casida, 2003). In North America, neonicotinoids have mostly been used as seed treatments to control a variety of foliar and soil early-season insect pests in corn, soybean, wheat and other important crops (Elbert et al., 2008; Samson-Robert et al., 2014; Douglas and Tooker, 2015). These treatments are most widely applied prophylactically, without any information on the actual presence of the targeted pests. Hence, previous studies have indicated that neonicotinoids often have no significant impact on crop yield (Cox and Cherney, 2011; Reisig et al., 2012; Penn and Dale, 2017; Alford and Krupke, 2018). A recent study that has extensively evaluated yield variations in response to neonicotinoid seed treatment with regards to the abundance and incidence of pest populations has reported that there is no significant difference in crop yield when pest pressure is low, which was the case in most of the sites under study (Labrie et al., 2020). The neonicotinoid compounds are tiny molecules and are highly soluble in water (Bonmatin et al., 2015). Given their systemic nature, plants take them up from the seed covering and translocate them to different tissues and products, including nectar, guttation and pollen (Sur and Stork, 2003; Bonmatin et al., 2005; Girolami et al., 2009). Neonicotinoids may remain active from 20-30 days in soybean (Myers and Hill, 2014) and corn (Alford and Krupke, 2017) to 200 days in winter wheat (Zhang et al., 2016). Plants only absorb about $20 \%$ of the seed covering (Sur and Stork, 2003; Alford and Krupke, 2017). The rest of the pesticide persists in soil for up to 3 years, depending on its active ingredient and the soil properties (e.g., soil type, organic matter content and pH) (Goulson, 2013; Bonmatin et al., 2015). During the last decades, many questions have been raised about the potential impacts of the widespread and prophylactic (Goulson, 2013; Labrie et al., 2020) use of neonicotinoids on non-target organisms. Past studies have shown some negative effects of neonicotinoids on agriculturally beneficial organisms, including beneficial soil invertebrates like earthworms (Pisa et al., 2015), and insect pollinators, particularly honeybees (Iwasa et al., 2004; Samson-Robert et al., 2014, 2017; Sanchez-Bayo and Goka, 2014; Bonmatin et al., 2015). Although neonicotinoids target organisms that possess a nervous system and the nAChRs, some studies have reported that they have non-target impacts on the functions and structure of microbial communities, such as fungal (Moulas et al., 2013) and bacterial structure, abundance and community composition in phyllosphere (Zhang et al., 2008, 2009; Moulas et al., 2013) and soil (Cycoń et al., 2013; Yu et al., 2020). Previous biochemical or culture-based microbiological studies have also confirmed the effects of these insecticides on bacterial respiration, phosphatase activity, and other 
enzyme activities, including ammonification, nitrification, and denitrification (Singh and Singh, 2006; Ahemad and Khan, 2012; Cycoń and Piotrowska-Seget, 2015; Filimon et al., 2015).

Soybean and corn are two important agricultural crops and are among those that are typically treated by pesticides, including neonicotinoids. In this study, we aim to (1) characterize the drivers of variation in bacterial community structure of soybean and corn phyllosphere and soil and (2) identify the responses of bacterial community composition variation and diversity to neonicotinoid seed treatment in a 3-year soybean/corn rotation. We hypothesized that (1) habitat, host species and time will all contribute to variation in bacterial community composition and diversity, and (2) neonicotinoid seed treatment will cause a shift in the bacterial community composition and a decrease in bacterial diversity of both phyllosphere and soil. We address these objectives and hypotheses by quantifying bacterial community structure using bacterial 16S rRNA gene amplicon sequencing in soybean and corn phyllosphere and soil samples collected over 3 years in Quebec, Canada.

\section{MATERIALS AND METHODS}

\section{Study Site}

We cultivated a 3-year rotation of soybean (2016 and 2018) and corn (2017) on the Agriculture and Agri-Food Canada experimental farm in L'Acadie (ACA) $\left(45^{\circ} 17^{\prime} 38.0^{\prime \prime} \mathrm{N}\right.$; $\left.73^{\circ} 20^{\prime} 58.0^{\prime \prime} \mathrm{W}\right)$, Quebec, Canada. L'Acadie is located in Canadian hardiness zone $5 \mathrm{a}$. The region is characterized by having a clay loam soil type and a temperate climate. In mid-May of each year, we sowed soybean or corn on a $100 \mathrm{~m} \times 30 \mathrm{~m}$ field, previously a meadow, that had not received neonicotinoid application during the 3 years preceding the experiment. Four replicates of each non-neonicotinoid (control) and neonicotinoid-treated plots $(100 \mathrm{~m} \times 3 \mathrm{~m})$ were established alternately and consisted of four rows each. Two extra neonicotinoid-treated plots surrounded the experimental field. Soybean and corn seeds were coated with three fungicides (difenoconazole, metalaxyl-M, and sedaxane) in both control and treated plots. The neonicotinoid-treated seeds were also covered by thiamethoxam at $0.25 \mathrm{mg} / \mathrm{seed}$. The fields were under no-till farming, and glyphosate was applied twice during each growing season (before seeding and one month after it) to control weeds. The corn field was also fertilized with $400 \mathrm{~kg} / \mathrm{ha}$ NPK (15-15-15) before seeding and $222 \mathrm{~kg} / \mathrm{ha} \mathrm{N}$ (27.5\%) 1 month after seeding. Soil physicochemical properties (e.g., pH, etc.) were constant across the experimental field and did not differ between the growing seasons (Supplementary Table 1).

\section{Sample Collection}

To study the phyllosphere bacteria (the bacteria collected from the leaf surface in our case), each year we collected 48 samples (two samples per plot at three sampling times during the growing seasons), for a total of 144 samples. The three annual sampling occasions happened in July, August and September. We sampled 50-100 g of healthy mature middle leaves of 6-10 close plants from the two middle rows of each plot. We then stored each sample in a sterile plastic bag and transferred it to the laboratory in a cooler, surrounded by ice packs. We immediately collected the bacterial cells from the leaves by washing them in a $0.85 \%$ saline solution and agitating the solution using a stomacher at $250 \mathrm{rpm}$ for $30 \mathrm{~s}$. We then transferred the solutions to $50-\mathrm{ml}$ tubes, centrifuged them at 4,000 $\mathrm{g}$ for $20 \mathrm{~min}$ and discarded the supernatants. We kept the remaining pellets at $-80^{\circ} \mathrm{C}$ until use.

To study the soil bacteria, we sampled bulk soil (soil that does not adhere to plant roots) from the upper $12-15 \mathrm{~cm}$ layer of soil with a corer $(2 \mathrm{~cm}$ in diameter) from the soil around the same plants that we sampled for the phyllosphere. For each soil sample, we collected soil from six different spots, in a zigzag pattern and at $10 \mathrm{~cm}$ from the plants, and then mixed and pooled them into one 400-500 g sample (Sugiyama et al., 2014; Gagic et al., 2017). We transferred samples to the laboratory in a cooler and stored at $-80^{\circ} \mathrm{C}$ until use. Each year, we collected 48 soil samples (two samples per plot at the same three sampling times as phyllosphere), for a total of 144 samples.

\section{DNA Extraction}

We extracted DNA from the samples of phyllosphere (pellets containing bacterial cells) and soil (directly) using MoBio PowerSoil DNA isolation kit (QIAGEN). Considering the high amount of material to be extracted from each soil sample, we extracted DNA twice, each time from $0.5 \mathrm{~g}$ of the same sample, and pooled the extractions together in order to better capture soil bacterial community variation. The rest of the extraction was performed according to the manufacturer's instructions. Then, we measured the concentration and quality of the extracted DNA using Qubit (Thermo Fisher Scientific) and Nanodrop (Thermo Fisher Scientific) prior to storing them at $-80^{\circ} \mathrm{C}$.

\section{Bacterial DNA Amplification}

Following previously described protocols (Kembel et al., 2014; Laforest-Lapointe et al., 2016b; Kim et al., 2018), we amplified the V5-V6 hypervariable regions of the bacterial 16S rRNA gene, using chloroplast-excluding primers [16S primers $799 \mathrm{~F}-1115 \mathrm{R}$ (Chelius and Triplett, 2001; Redford et al., 2010)]. We added variable length barcodes and Illumina adaptor sequence to the $5^{\prime}$ end of the primers. Each PCR reaction $(25 \mu \mathrm{L})$ contained $1 \mu \mathrm{L}$ of genomic DNA (1:10 dilution for soil samples), $5 \mu \mathrm{L} 5 \mathrm{xHF}$ buffer (Thermo Scientific), $0.5 \mu \mathrm{L}$ dNTPs (10 mM each), $0.75 \mu \mathrm{L}$ DMSO, $0.25 \mu \mathrm{L}$ Phusion Hot Start II polymerase (Thermo Scientific), $1.0 \mu \mathrm{L}$ of each primer $(5 \mu \mathrm{M})$, and $15.50 \mu \mathrm{L}$ doubledistilled water. We amplified the bacterial DNA in an Agilent SureCycler 8,800 using the following conditions: $98^{\circ} \mathrm{C}$ for $30 \mathrm{~s}$, 35 cycles of $98^{\circ} \mathrm{C}, 15$-s denaturation; $64^{\circ} \mathrm{C}, 30$-s annealing, and $72^{\circ} \mathrm{C}$, 30-s elongation; followed by a final elongation at $72^{\circ} \mathrm{C}$, $10 \mathrm{~min}$. All samples were distributed randomly into several 96-well PCR plates for DNA amplification. Each PCR plate contained one positive and one negative control. Each positive control included Clavibacter michiganensis, Pectobacterium sp., E. coli DHS alpha, Pantoea stewartii and Xanthomonas sp., while the negative controls were nuclease-free, DEPC-treated and autoclaved water. We also had negative controls of the sampling plastic bags, tubes and the extraction kit. All PCR products were electrophoresed on a $2 \%$ agarose gel in $1 \mathrm{X}$ TAE buffer, stained 
with AMRESCO's EZ-Vision dye as loading buffer (VWR Life Science), and visualized by G:BOX gel doc (Syngene).

\section{Normalization, Library Preparation and Sequencing}

All PCR products were normalized using SequalPrep PCR Normalization kit (Thermo Fisher Scientific). One library per PCR plate was prepared by pooling all the amplified and normalized DNA. The concentration of each library was determined using Qubit. For each sequencing run, an equimolar concentration of each library was pooled and purified using Ampure XP (Beckman Coulter by Thermo Fisher Scientific), according to the manufacturer's protocol. We used Qubit and Bioanalyzer DNA analysis kit (Agilent) to verify the final concentration and quality of the purified DNA. According to MiSeq Illumina guidance, the $4 \mathrm{nM}$ DNA was denatured using $\mathrm{NaOH} 0.2 \mathrm{~N}$ and then diluted to a $14 \mathrm{pM}$ library. Then, it was $\mathrm{PE}$ (paired-end) sequenced on Illumina MiSeq $(2 \times 300 \mathrm{bp})$, using a 600-cycle MiSeq reagent kit v3, at Agriculture and AgriFood Canada.

\section{Bioinformatic Analyses}

We used BBDuk ${ }^{1}$ to remove Illumina adapters. We also removed barcodes and primers and then demultiplexed the Illumina reads. Afterward, we applied DADA2 v1.12.1 (Callahan et al., 2016) to remove low-quality sequences, correct the Illumina-sequencing amplicon errors, merge paired-end sequences, eliminate chimeric sequences, and identify amplicon sequence variants (ASVs). We used default parameter settings for all functions except for the following functions: (i) in filterAndTrim function, we removed all the sequences with fewer than 50 nucleotides $($ minLen $=50$, instead of 20), (ii) in dada function, we set the algorithm to perform pseudo-pooling between samples, and (iii) in mergePairs, we set a minimum overlap length of 10 (minOverlap $=10$, instead of 12$)$ in order to merge the forward and reverse reads. We finally used the RDP naive Bayesian classifier method implemented in DADA2 with the SILVA 132 rRNA database (Quast et al., 2013; Yilmaz et al., 2014) to annotate the taxonomic identity of ASVs.

\section{Sample Quality Control, Decontamination and Rarefaction}

After verifying the presence and composition of the mock communities in the positive controls, we removed them from the dataset. To minimize sequence artifacts caused by PCR and sequencing errors (Acinas et al., 2005), which may result in spurious ASVs, we performed the following steps of quality filtering and decontamination: (1) removing ASVs that were not taxonomically annotated as belonging to a bacterial phylum ( $0.78 \%$ of all sequences); (2) eliminating the outlier samples (including two of the negative control samples) that had a very different composition from the other samples based on the non-metric multidimensional scaling (NMDS) on BrayCurtis dissimilarities (Bray and Curtis, 1957); (3) filtering all the samples with less than 1,000 sequences (39 samples, including

\footnotetext{
${ }^{1}$ http://jgi.doe.gov/data-and-tools/bb-tools/
}

all the other negative controls, except for the phyllosphere and soil sampling bag controls); (4) removing the contaminating DNA from the bacterial communities using the prevalence method (probability threshold $=0.5$ ) of the decontam package v1.1.2 (Davis et al., 2018) in R v4.0.0 (R Core Team, 2019), which identified 50 ASVs as contaminants based on the most prevalent ASVs in the negative controls; (5) eliminating all the ASVs recognized as chloroplasts or mitochondria (0.15\%); (6) excluding the samples with low alpha diversity (Shannon richness $<2$, including the soil sampling bag control and one phyllosphere sample); (7) removing the rare ASVs with less than 10 reads (37\% of ASVs); and (8) eliminating again the outlier samples detected in the denoised dataset (five samples, including the last remaining negative control, one phyllosphere and four soil samples), which had a highly different composition (based on NMDS on Bray-Curtis dissimilarities) or species richness (based on Shannon diversity) from the other samples of the same habitat. Finally, we selected cutoffs to rarefy samples based on inspection of rarefaction curves for phyllosphere and soil samples, choosing rarefaction cutoffs that approached saturation in the ASV rarefaction curve while keeping as many samples as possible. We first rarefied the soybean and corn phyllosphere and soil samples to 5,000 reads per sample, which excluded 12 samples that contained insufficient numbers of sequences and 699 ASVs. We then made a subset of nontreated (control) samples (119 samples and 13,042 ASVs) to study the soybean and corn phyllosphere and soil bacterial community diversity and composition. We also made a subset of phyllosphere samples (110 samples and 6,695 ASVs) to study the variations in the phyllosphere bacterial community diversity and composition in response to neonicotinoid seed treatment. Since soil samples had more sequences per sample than phyllosphere samples, we rarefied the dataset again, this time to 10,000 reads per sample, which excluded 22 samples that contained insufficient numbers of sequences and 195 ASVs. Therefore, we subset soil samples to study the effects of neonicotinoid seed treatment on their bacterial diversity and composition (132 samples and 13,137 ASVs). Overall, quality control and filtering, decontamination, and rarefaction procedures at 5,000 and 10,000 cutoffs (Figure 1), respectively, eliminated 41 and 39\% of the low-quality ASVs and 20 and $23 \%$ of the samples (including all the 15 negative controls). We then analyzed these datasets using different $\mathrm{R}$ packages.

\section{Statistical Analyses Characterization of Phyllosphere and Soil Bacterial Composition and Diversity}

To identify the bacterial composition and diversity of the soybean and corn phyllosphere and soil, we analyzed the nonneonicotinoid treated (control) samples that were rarefied to 5,000 reads per sample. This dataset contained 119 samples (including 30 soybean and 21 corn phyllosphere samples, as well as 45 soybean and 23 corn soil samples) with an average of $1,174 \pm 65.0$ ASVs (mean \pm SE) per sample. We conducted permutational multivariate analyses of variance (PERMANOVA) (Anderson, 2001) using the adonis2 function 


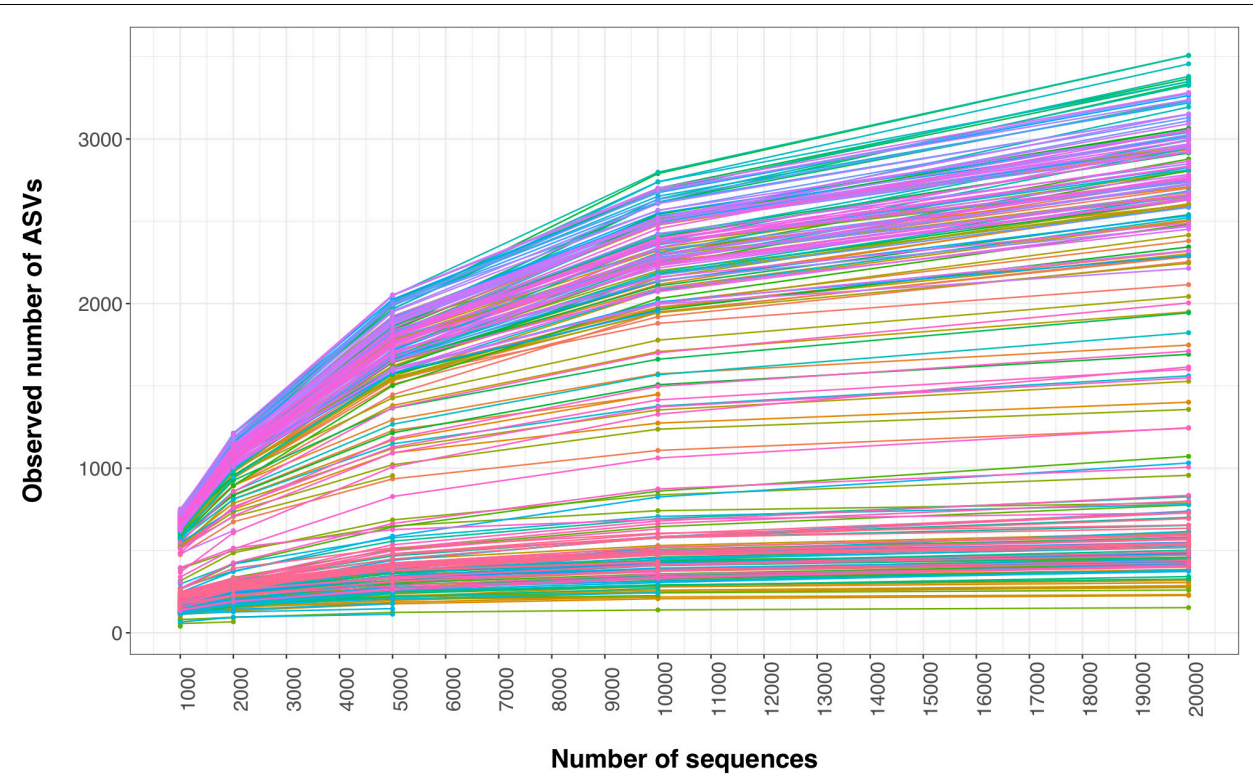

FIGURE 1 | Rarefaction curves of the phyllosphere and soil bacterial ASVs. Rarefaction curves are shown for all the phyllosphere and soil samples according to the observed ASVs richness. Each line and color represent one sample. The sequencing coverage ( $x$-axis: number of sequences) is 20,000 reads with cutoffs at 1,000 , $2,000,5,000$, and 10,000 reads.

of the vegan package in $\mathrm{R}$ with 999 permutations first on the whole community dissimilarity matrix to test for the effects of habitats (phyllosphere and soil), host species (soybean and corn), time (month and year), and their interactions on the bacterial composition variation (model:. $\sim$ habitat $*$ host species * month/year), and then on each habitat individually to test for the effects of host species, time and their interactions on the bacterial community composition (model:. $\sim$ host species * month/year).

To assess the bacterial community homogeneity of each habitat and also each host species individually in phyllosphere and soil, we used a multivariate homogeneity test of groups dispersions using the betadisper function of the vegan package in $\mathrm{R}$ and then performed an analysis of variance (ANOVA)like permutation test with 999 permutations to evaluate the significance of the results.

Furthermore, we used the Shannon index to estimate the soybean and corn phyllosphere and soil bacterial alpha diversity. We conducted the non-parametric Wilcoxon rank-sum test (Wilcoxon, 1945) to compare the Shannon diversity for the following groups: between phyllosphere versus soil samples, and individually in each habitat between soybean versus corn samples, among years, and among months. This test was applied to determine the statistically significant differences of the bacterial ASVs richness among the mentioned groups. We adjusted the $P$-values using Holm's method (Holm, 1979).

To understand which families drove the variation in bacterial composition across habitats and hosts, we studied the correlations among all the bacterial families of soybean and corn phyllosphere and soil, which had an average relative abundance of more than 0.01 , with their habitats and hosts. To achieve this, we used the envfit function of the vegan package in $R$, which computes the goodness of fit values $\left(\mathrm{R}^{2}\right)$ and their significance (with 999 permutations) of the vectors of bacterial families relative abundance onto the principal coordinate analysis (PCoA) ordination (based on Bray-Curtis distances).

\section{Effects of Neonicotinoid Seed Treatment on Bacterial Community Composition, Diversity, and Temporal Variation}

To study the bacterial community variations in response to neonicotinoid seed treatment, we separately analyzed the rarefied phyllosphere (5,000 reads per sample) and soil (10,000 reads per sample) samples. The phyllosphere dataset contained 110 samples (including 67 soybean and 43 corn samples) with an average of $391.1 \pm 20.3$ ASVs (mean \pm SE) per sample, and the soil dataset contained 132 samples (including 85 soybean and 47 corn samples) with an average of $2,257 \pm 30.0$ ASVs (mean \pm SE) per sample. We evaluated the relationships between bacterial communities and their host species, time (year and month) and neonicotinoid seed treatment, using a PERMANOVA with 999 permutations on the community matrix (model:. $\sim$ host species $*$ year $*$ month $*$ neonicotinoid seed treatment) for each habitat individually. We also performed a PCoA (on BrayCurtis dissimilarities) per habitat to illustrate the composition variation in the bacterial communities. Given the strong effects of host plants on the phyllosphere (Knief et al., 2010; Kembel et al., 2014; Laforest-Lapointe et al., 2016b) and soil (Wieland et al., 2001) bacterial community structure and according to our preliminary results, we also studied the soybean and corn samples individually to understand whether the impacts of neonicotinoid seed treatment on the patterns of bacterial community variation were masked by host species. Thereafter for each crop, we performed a PCoA (based on Bray-Curtis distances) and a PERMANOVA test (model:. $\sim$ year ${ }^{*}$ month $*$ neonicotinoid 
seed treatment) to explore the phyllosphere and soil bacterial community composition and the drivers of its variation.

We used the Shannon index to determine the phyllosphere and soil bacterial alpha diversity. Then, we conducted the nonparametric Wilcoxon rank-sum test to compare the Shannon diversity between the control versus neonicotinoid-treated samples in each habitat, as well as in soybean and corn separately for each habitat (model: Shannon $\sim$ neonicotinoid seed treatment). For each habitat individually, we used a linear model to evaluate the effects of neonicotinoid application on the bacterial alpha diversity across time (phyllosphere model: Shannon $\sim$ neonicotinoid seed treatment ${ }^{*}$ month; soil model: Shannon $\sim$ neonicotinoid seed treatment $*$ month $*$ year), followed by an ANOVA test to determine the significant interactions. We then used the Wilcoxon rank-sum test, in which we grouped the samples by month (phyllosphere and soil models: Shannon $\sim$ neonicotinoid seed treatment, group by $=$ month) and by year (soil model: Shannon $\sim$ neonicotinoid seed treatment, group by = year) to identify the significance of the interactions suggested by our model. We adjusted the $P$-values using Holm's method.

\section{Effects of Neonicotinoid Seed Treatment on Bacterial Taxonomic Composition}

To determine the differentially abundant ASVs and taxa between control and neonicotinoid-treated samples in each habitat, we performed a differential expression analysis of sequence data [DESeq2 (Love et al., 2014)] using the Wald significance test with a local fit type and compared the results by estimating the log2 fold changes. We analyzed the non-rarefied and non-normalized quality filtered and decontaminated bacterial phyllosphere (118 samples, including 58 control and 60 neonicotinoid-treated samples) and soil samples (137 samples, including 69 control and 68 neonicotinoid-treated samples) separately to identify the differentially abundant ASVs and taxa using the DESeq2 test. We then adjusted the $P$-values (significance cutoff of 0.05 ) using the Benjamini-Hochberg false-discovery rate (FDR) method (Hochberg and Benjamini, 1990) to identify the significantly differentially abundant ASVs and taxa between the control and neonicotinoid-treated samples during 3 years of rotation individually for each habitat.

\section{RESULTS}

\section{Effects of Habitat, Host Species and Time on the Phyllosphere and Soil Bacterial Communities}

In this experiment, the habitat (phyllosphere versus soil) was the strongest driver of bacterial community variation. Habitat alone explained $37.3 \%$ of the community variation, while host plant species (soybean versus corn) explained only 3.2\%, and their interaction 3.7\% (PERMANOVA $P<0.001$, Table 1). Community composition was significantly more homogenous among soil samples than phyllosphere samples (average distance to median 0.42 versus 0.50 , ANOVA on multivariate homogeneity of groups dispersions $F=24.13, P<0.001$ ) and the phyllosphere communities exhibited less variation in corn than in soybean (average distance to median 0.38 versus 0.48 , ANOVA on multivariate homogeneity of groups dispersions $F=6.20, P<0.05$, Figure 2A). Bacterial alpha diversity was significantly higher in soil than in the phyllosphere (Shannon index mean \pm SE $7.0 \pm 0.02$ versus $4.2 \pm 0.10$, Wilcoxon adjusted $P<0.0001)$. The relative abundance of several bacterial families was strongly associated with soil (such as Gemmatimonadaceae and Solibacteraceae), soybean phyllosphere (such as Beijerinckiaceae and Rhizobiaceae) or corn phyllosphere (such as Sphingomonadaceae and Hymenobacteraceae $)(P<0.001$, envfit analysis of correlation between PCoA axes and variables, Figure 2B and Supplementary Table 2).

Time was also a significant determinant of bacterial community variation, particularly in the phyllosphere habitat. Month and year together explained $2.9 \%$ of the whole bacterial community composition variation while the interactions between time, habitat and host species explained $7.2 \%$ of the variation (PERMANOVA $P<0.001$, Table 1). Time was a much greater

TABLE 1 | Main drivers of the phyllosphere and soil bacterial community composition variation in a 3-year soybean/corn rotation.

\begin{tabular}{|c|c|c|c|c|c|c|c|c|c|}
\hline \multirow[b]{2}{*}{ Variables } & \multicolumn{3}{|c|}{ Phyllosphere and soil } & \multicolumn{3}{|c|}{ Phyllosphere } & \multicolumn{3}{|c|}{ Soil } \\
\hline & $R^{2}(\%)$ & $\boldsymbol{F}$ & $\operatorname{Pr}(>F)$ & $\mathrm{R}^{2}(\%)$ & $\boldsymbol{F}$ & $\operatorname{Pr}(>F)$ & $\mathbf{R}^{2}(\%)$ & $\boldsymbol{F}$ & $\operatorname{Pr}(>F)$ \\
\hline Habitat & 37.3 & 100.98 & $0.001^{\star \star \star}$ & & & & & & \\
\hline Host species & 3.2 & 8.69 & $0.001^{\star \star \star}$ & 18.6 & 19.62 & $0.001^{\star \star \star}$ & 2.5 & 1.83 & $0.007^{\star \star}$ \\
\hline Month/Year & 2.9 & 3.93 & $0.001^{\star \star \star}$ & 15.7 & 8.28 & $0.001^{\star \star \star}$ & 4.6 & 1.66 & $0.002^{\star \star}$ \\
\hline Habitat: Host species & 3.7 & 10.07 & $0.001^{\star \star \star}$ & & & & & & \\
\hline Habitat: Month/Year & 3.6 & 4.9 & $0.001^{\star \star \star}$ & & & & & & \\
\hline Host species: Month/Year & 2.1 & 2.89 & $0.005^{\star \star}$ & 11.4 & 6.02 & $0.001^{\star \star \star}$ & NS & NS & NS \\
\hline Host species: Month: Year & 2.5 & 2.97 & $0.005^{\star \star}$ & 14.6 & 5.14 & $0.001^{\star \star \star}$ & 8 & 1.94 & $0.001^{\star \star \star}$ \\
\hline Habitat: Host species: Month & 2.5 & 3.35 & $0.003^{\star \star}$ & & & & & & \\
\hline Habitat: Host species: Month: Year & 7.2 & 3.26 & $0.001^{\star \star \star}$ & & & & & & \\
\hline
\end{tabular}

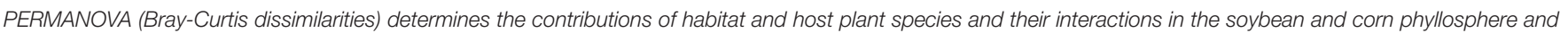

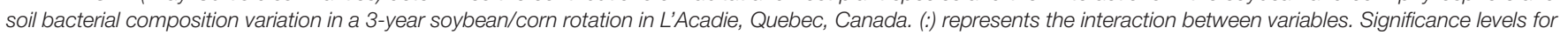
each variable are given by: ${ }^{* *} P<0.001 ;{ }^{\star *} P<0.01 ;{ }^{*} P<0.05 ; N S, P \geq 0.05$. 


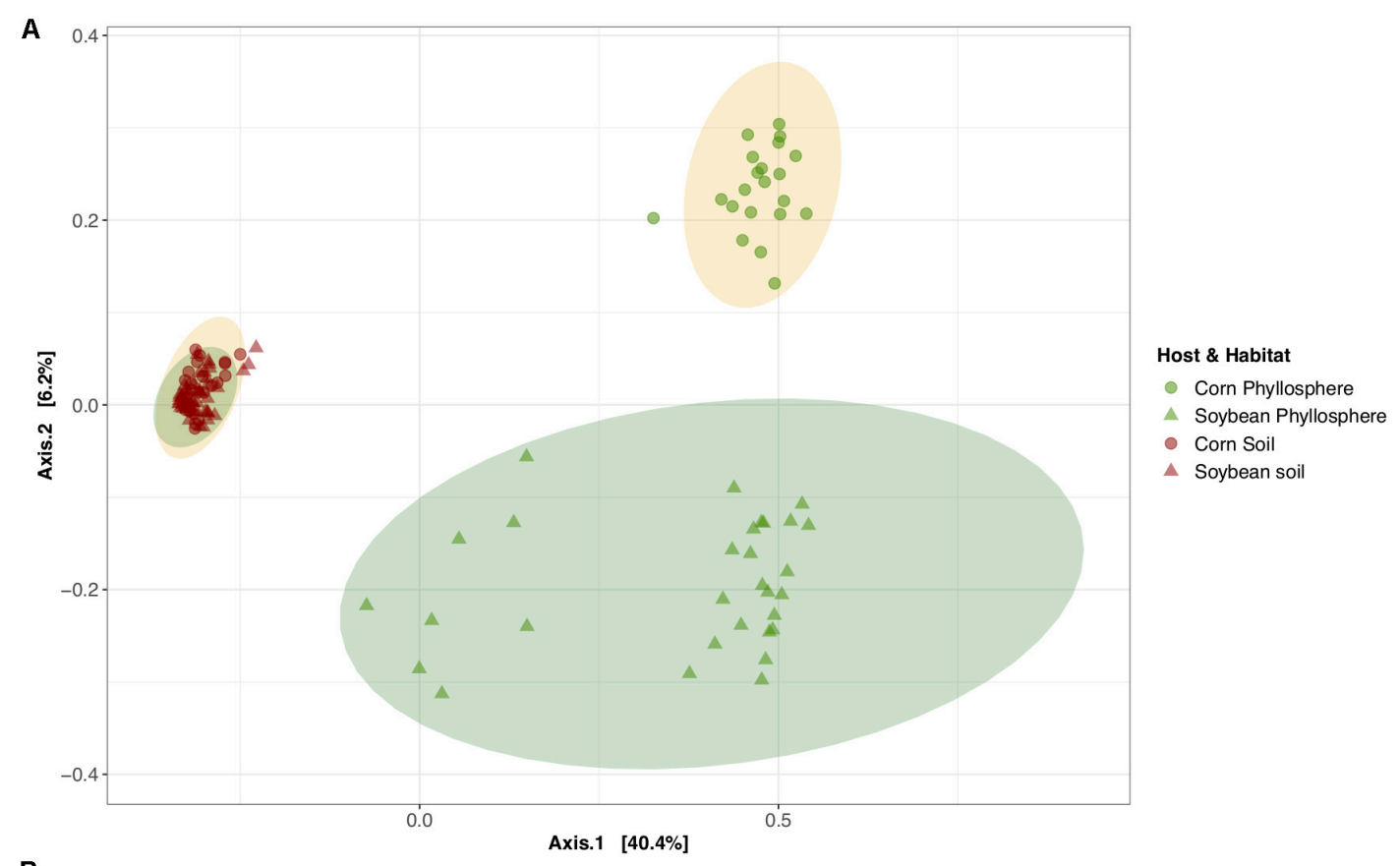

B

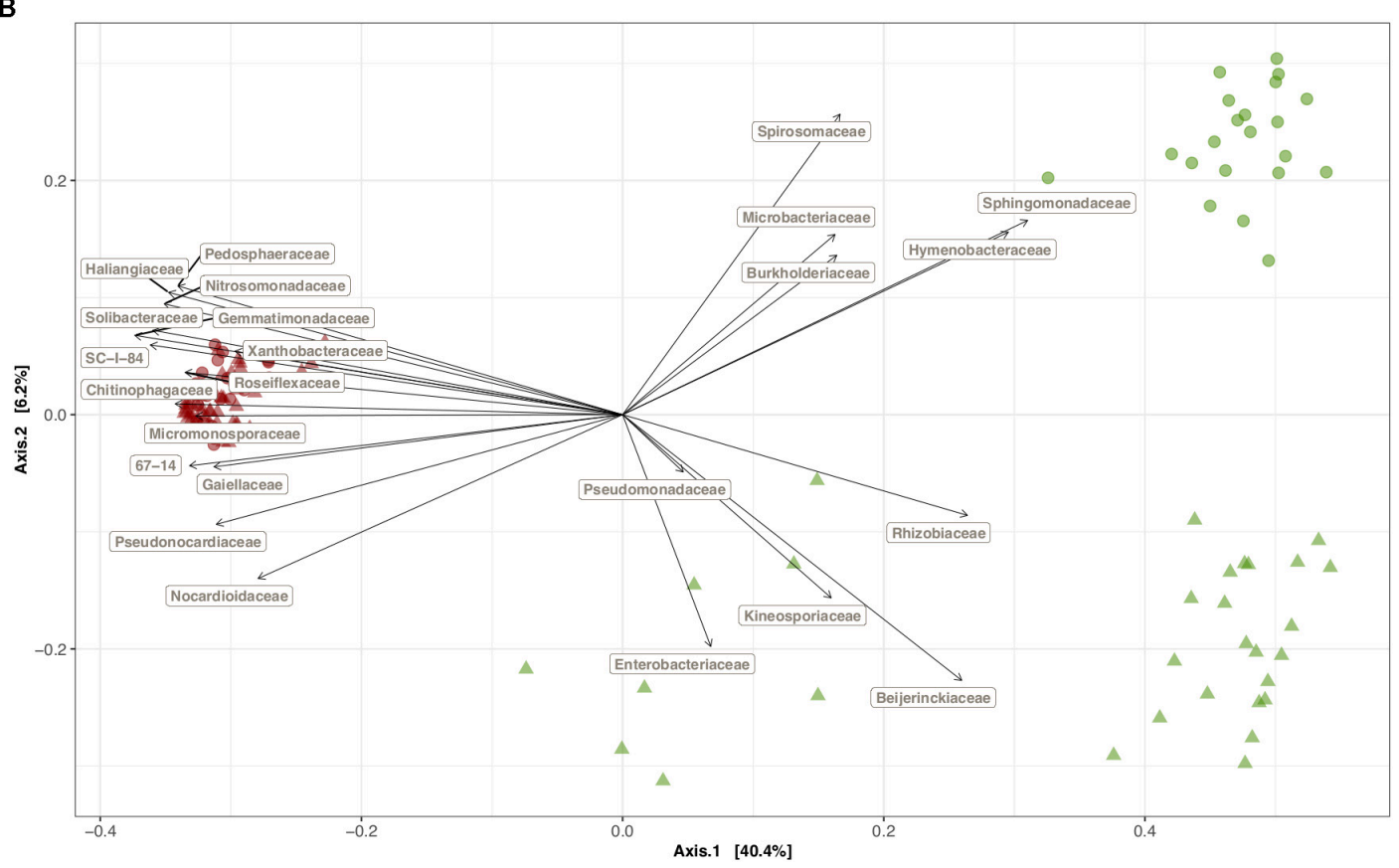

FIGURE 2 | Soybean and corn phyllosphere and soil bacterial community diversity and the families who are driving this diversity pattern. Principal coordinate analysis (PCoA) on Bray-Curtis dissimilarities (A) of the bacterial community composition and the correlations between bacterial family abundances and different axes of the PCoA ordination (B) in the phyllosphere and soil bacterial communities in a 3-year soybean/corn rotation in L'Acadie, Quebec, Canada. Ordinations show that habitat (red points: soil, green points: phyllosphere) and host species (circle points: corn, triangle points: soybean) explain the bacterial community composition variations. The axes of the ordinations explain $46.6 \%$ of the variation in the bacterial community composition. Ellipses (A) are shaded based on host species (yellow for corn and green for soybean samples) and represent a 99\% confidence level. Gray arrows (B) indicate the significant correlations (P=0.001, except for the Pseudomonadaceae family) among the bacterial families that had an average relative abundance of more than 0.01 and their habitat and host species. Arrows directions show the correlations among habitats and host species and arrow length indicates the strength of these correlations.

driver of community composition variation in the phyllosphere than in soil $(15.7 \%$ versus $4.6 \%$, PERMANOVA $P<0.001$, Table 1). Alpha diversity varied in time in the phyllosphere but not in soil (Table 2). This effect in the phyllosphere was especially obvious between the first and the last year of the rotation where diversity was highest in the last year (Shannon index mean $\pm \mathrm{SE}$, 
TABLE 2 | Bacterial alpha diversity explained by time (year and month) and neonicotinoid seed treatment.

\begin{tabular}{|c|c|c|c|c|c|c|}
\hline \multirow[t]{2}{*}{ Variables } & & \multicolumn{2}{|c|}{ Phyllosphere } & \multicolumn{2}{|c|}{ Soil } & \multirow[b]{2}{*}{ Subset } \\
\hline & & Mean \pm SE & Adjusted $\boldsymbol{P}$-value & Mean \pm SE & Adjusted $P$-value & \\
\hline \multirow[t]{2}{*}{ Host species } & Soybean & $4.4 \pm 0.15$ & NS & $7.0 \pm 0.03$ & NS & \\
\hline & Corn & $4.0 \pm 0.12$ & & $7.0 \pm 0.04$ & & \\
\hline \multirow[t]{6}{*}{ Year } & 2016 & $4.0 \pm 0.17$ & NS & $7.0 \pm 0.05$ & NS & \\
\hline & 2017 & $4.0 \pm 0.12$ & & $7.0 \pm 0.04$ & & \\
\hline & 2017 & $4.0 \pm 0.12$ & $<0.01^{\star \star}$ & $7.0 \pm 0.04$ & NS & \\
\hline & 2018 & $4.8 \pm 0.20$ & & $7.1 \pm 0.02$ & & \\
\hline & 2016 & $4.0 \pm 0.17$ & $<0.0001^{\star \star \star \star}$ & $7.0 \pm 0.05$ & NS & \\
\hline & 2018 & $4.8 \pm 0.20$ & & $7.1 \pm 0.02$ & & \\
\hline \multirow[t]{6}{*}{ Month } & July & $4.6 \pm 0.30$ & $<0.05^{\star}$ & $7.0 \pm 0.03$ & NS & \\
\hline & August & $3.8 \pm 0.11$ & & $7.0 \pm 0.04$ & & \\
\hline & August & $3.8 \pm 0.11$ & $<0.001^{\star \star \star}$ & $7.0 \pm 0.04$ & NS & \\
\hline & September & $4.4 \pm 0.86$ & & $6.9 \pm 0.04$ & & \\
\hline & July & $4.6 \pm 0.30$ & NS & $7.0 \pm 0.03$ & $<0.05^{\star}$ & \\
\hline & September & $4.4 \pm 0.86$ & & $6.9 \pm 0.04$ & & \\
\hline \multirow[t]{6}{*}{ Treatment and host species } & Control & $4.2 \pm 0.10$ & NS & $7.2 \pm 0.02$ & $<0.001^{\star \star \star}$ & Soybean and Corn \\
\hline & NST & $4.1 \pm 0.08$ & & $7.0 \pm 0.03$ & & \\
\hline & Control & $4.4 \pm 0.15$ & NS & $7.2 \pm 0.03$ & $<0.01^{\star \star}$ & Soybean \\
\hline & NST & $4.2 \pm 0.10$ & & $7.1 \pm 0.03$ & & \\
\hline & Control & $4.0 \pm 0.12$ & NS & $7.1 \pm 0.05$ & $<0.01^{\star \star}$ & Corn \\
\hline & NST & $3.9 \pm 0.10$ & & $7.0 \pm 0.05$ & & \\
\hline \multirow[t]{6}{*}{ Treatment and month } & Control & $4.6 \pm 0.30$ & NS & $7.2 \pm 0.03$ & $<0.001^{\star \star \star}$ & July \\
\hline & NST & $4.4 \pm 0.20$ & & $7.0 \pm 0.04$ & & \\
\hline & Control & $3.8 \pm 0.11$ & NS & $7.2 \pm 0.04$ & $<0.001^{\star \star \star}$ & August \\
\hline & NST & $3.8 \pm 0.11$ & & $7.0 \pm 0.05$ & & \\
\hline & Control & $4.4 \pm 0.09$ & NS & $7.1 \pm 0.05$ & NS & September \\
\hline & NST & $4.2 \pm 0.08$ & & $7.1 \pm 0.05$ & & \\
\hline \multirow[t]{6}{*}{ Treatment and year } & Control & & & $7.1 \pm 0.05$ & NS & 2016 \\
\hline & NST & & & $7.0 \pm 0.05$ & & \\
\hline & Control & & & $7.1 \pm 0.05$ & $<0.01^{\star \star}$ & 2017 \\
\hline & NST & & & $6.9 \pm 0.05$ & & \\
\hline & Control & & & $7.2 \pm 0.03$ & NS & 2018 \\
\hline & NST & & & $7.2 \pm 0.03$ & & \\
\hline
\end{tabular}

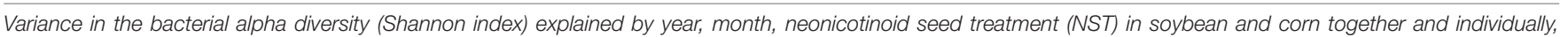

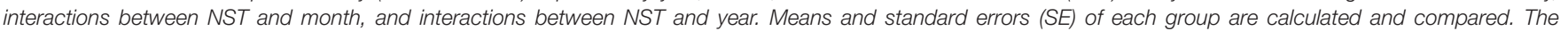

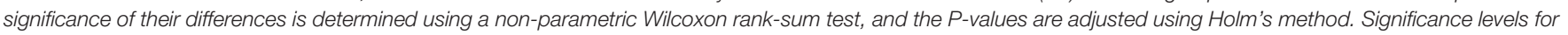
each variable are given by: ${ }^{\star * * *} P<0.0001 ;{ }^{* * *} P<0.001 ;{ }^{* *} P<0.01 ;{ }^{*} P<0.05$; NS: $P \geq 0.05$.

respectively, $4.0 \pm 0.17$ versus $4.8 \pm 0.20$, Wilcoxon adjusted $P<0.0001$, Table 2) but we also observed intra-annual variation in diversity (Table 2).

\section{Effects of Neonicotinoid Seed Treatment on Bacterial Communities}

Neonicotinoid seed treatment showed complex effects on the composition of bacterial communities. Neonicotinoid treatment alone explained a small but significant portion of the variation in both the phyllosphere (1.3\%) and soil (2.6\%) (PERMANOVA $P<0.01$, Table 3 ). Since the bacterial composition varied greatly among host species and time (Table $\mathbf{3}$ and Figure $\mathbf{3}$ ), the impacts of neonicotinoid seed treatment were partially masked by this variation. Effects of neonicotinoid treatment were especially evident in soils in the middle of the growing season
(Figure 3C). To uncover neonicotinoid impacts, we analyzed each crop species separately, which revealed a much stronger effect of the neonicotinoid seed treatment on the composition of the phyllosphere communities in corn $(5.3 \%)$ than in soybean (1.6\%) (PERMANOVA $P<0.001$ and $P<0.05$, respectively, Table 3 and Figure 4). There was no significant difference in phyllosphere alpha diversity between neonicotinoid treatments overall, but soil bacterial alpha diversity was significantly higher in control versus neonicotinoid-treated samples (Shannon index mean \pm SE $7.2 \pm 0.02$ versus $7.0 \pm 0.03$, Wilcoxon adjusted $P<0.001$, Table 2).

The overall effect of neonicotinoid seed treatment on the temporal variation of bacterial community composition and alpha diversity was weak. In the phyllosphere, although there was a small significant effect of the interaction between neonicotinoid application and time (month and year) on variation in 
TABLE 3 | Drivers of the phyllosphere and soil bacterial community composition variation in response to neonicotinoid seed treatment in a 3-year soybean/corn rotation.

\begin{tabular}{|c|c|c|c|c|c|c|c|c|c|c|c|c|c|}
\hline \multirow[t]{2}{*}{ Variables } & \multirow{2}{*}{$\begin{array}{l}\text { Bray-Curtis } \\
\text { dissimilarities }\end{array}$} & \multicolumn{6}{|c|}{ Phyllosphere } & \multicolumn{6}{|c|}{ Soil } \\
\hline & & \multicolumn{2}{|c|}{ Soybean and corn } & \multicolumn{2}{|c|}{ Soybean } & \multicolumn{2}{|r|}{ Corn } & \multicolumn{2}{|c|}{ Soybean and corn } & \multicolumn{2}{|c|}{ Soybean } & \multicolumn{2}{|c|}{ Corn } \\
\hline \multirow[t]{2}{*}{ Host species } & $\mathrm{R}^{2}(\%)$ & & 14.7 & & & & & & 2.4 & & & & \\
\hline & $F \mid \operatorname{Pr}(>F)$ & 32.9 & $0.001^{\star \star \star}$ & & & & & 3.61 & $0.001^{\star \star \star}$ & & & & \\
\hline \multirow[t]{2}{*}{ Year } & $\mathrm{R}^{2}(\%)$ & & 7.4 & & 13.1 & & & & 5.7 & & 9.2 & & \\
\hline & $F \mid \operatorname{Pr}(>F)$ & 16.6 & $0.001^{* \star *}$ & 16.8 & $0.001^{\star * *}$ & & & 8.42 & $0.001^{\star \star *}$ & 8.92 & $0.001^{* \star *}$ & & \\
\hline \multirow[t]{2}{*}{ Month } & $\mathrm{R}^{2}(\%)$ & & 15.2 & & 28.3 & & 30 & & 2.6 & & 3.2 & & 5.8 \\
\hline & $F \mid \operatorname{Pr}(>F)$ & 16.96 & $0.001^{\star \star \star}$ & 18.27 & $0.001^{\star \star \star}$ & 9.25 & $0.001^{\star \star \star}$ & 1.89 & $0.001^{\star \star \star}$ & 1.55 & $0.012^{\star}$ & 1.39 & $0.036^{\star}$ \\
\hline \multirow[t]{2}{*}{ NST } & $\mathrm{R}^{2}(\%)$ & & 1.3 & & 1.6 & & 5.3 & & 2.6 & & 3.4 & & 3.7 \\
\hline & $F \mid \operatorname{Pr}(>F)$ & 2.81 & $0.002^{\star \star}$ & 2.12 & $0.021^{\star}$ & 3.3 & $0.001^{\star \star \star}$ & 3.82 & $0.001^{\star \star \star}$ & 3.33 & $0.001^{\star \star \star}$ & 1.78 & $0.017^{*}$ \\
\hline \multirow[t]{2}{*}{ NST: Host species } & $\mathrm{R}^{2}(\%)$ & & 1.2 & & & & & & NS & & & & \\
\hline & $F \mid \operatorname{Pr}(>F)$ & 2.56 & $0.002^{\star \star}$ & & & & & NS & NS & & & & \\
\hline \multirow[t]{2}{*}{ NST: Year } & $\mathrm{R}^{2}(\%)$ & & 0.8 & & NS & & & & 1.1 & & 1.8 & & \\
\hline & $F \mid \operatorname{Pr}(>F)$ & 1.73 & $0.043^{\star}$ & NS & NS & & & 1.63 & $0.030^{\star}$ & 1.73 & $0.014^{\star}$ & & \\
\hline \multirow[t]{2}{*}{ NST: Month } & $\mathrm{R}^{2}(\%)$ & & NS & & NS & & NS & & 2.4 & & NS & & 5.6 \\
\hline & $F \mid \operatorname{Pr}(>F)$ & NS & NS & NS & NS & NS & NS & 1.8 & $0.002^{\star \star}$ & NS & NS & 1.34 & $0.048^{*}$ \\
\hline \multirow[t]{2}{*}{ NST: Month: Host species } & $\mathrm{R}^{2}(\%)$ & & 1.4 & & & & & & NS & & & & \\
\hline & $F \mid \operatorname{Pr}(>F)$ & 1.55 & $0.028^{*}$ & & & & & NS & NS & & & & \\
\hline \multirow[t]{2}{*}{ NST: Year: Month } & $\mathrm{R}^{2}(\%)$ & & 1.4 & & NS & & & & NS & & NS & & \\
\hline & $F \mid \operatorname{Pr}(>F)$ & 1.57 & $0.026 *$ & NS & NS & & & NS & NS & NS & NS & & \\
\hline
\end{tabular}

PERMANOVA (Bray-Curtis dissimilarities) identifies the proportion of bacterial community composition variation explained by host plant species, time (year and month),

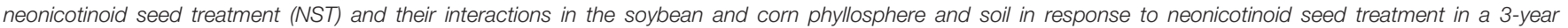

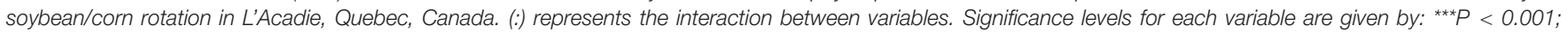
${ }^{* *} P<0.01 ;{ }^{*} P<0.05 ; N S, P \geq 0.05$.

community composition (1.4\%, PERMANOVA $P<0.05$, Table 3), the impacts on inter-annual variation and specific interactions with individual host species were not significant. The interaction of neonicotinoid seed treatment and time was slightly stronger in soil, especially with month (2.4\%, PERMANOVA $P<0.01$, Table 3). Uncovering these effects by studying each crop separately revealed that this month-to-month temporal variation in bacterial community structure within a growing season was particularly important in corn (5.6\%, PERMANOVA $P<0.05$, Table 3). Similarly, while the interaction between neonicotinoid seed treatment with time had no significant effect on bacterial alpha diversity in the phyllosphere, soil alpha diversity was significantly reduced in the neonicotinoid-treated samples in July and August (interaction between neonicotinoid seed treatment and month: linear regression analysis of Shannon index, $F=6.27$, ANOVA $P<0.001$; significant interactions among months and treatment: Shannon index, Wilcoxon $P<0.001$, Table 2).

\section{Bacterial Taxa Impacted by Neonicotinoid Seed Treatment}

Neonicotinoid seed treatment led to changes in the relative abundance of some phyllosphere and soil bacterial ASVs. Overall, we detected 34 bacterial ASVs in the phyllosphere and 294 in soil that were significantly differentially abundant between the control and neonicotinoid-treated samples. In the phyllosphere, 22 ASVs (mainly Bacteroidetes) were more abundant, and 12 (mainly Proteobacteria) were less abundant in response to neonicotinoid seed treatment (Table 4). The genera Hymenobacter (13 ASVs) and Pseudomonas (4 ASVs) were particularly favored by neonicotinoid treatment, while the genera Arsenophonus (4 ASVs) and Skermanella (3 ASVs) among others decreased in abundance in neonicotinoidtreated samples (DESeq 2 adjusted $P<0.05$, Figure $5 \mathrm{~A}$ and Supplementary Table 3). In soil, 68 ASVs (mainly Actinobacteria and Chloroflexi) were more abundant in the neonicotinoidtreated samples, while 226 (mainly Proteobacteria) were less abundant (Table 4). More than 60 genera of soil bacteria were significantly impacted by neonicotinoid treatment (Figure 5B and Supplementary Table 4). Genera negatively affected by neonicotinoid treatment included some of the beneficial soil bacteria (e.g., Ammoniphilus, Bacillus, Bosea, Bradyrhizobium, Hyphomicrobium, Mesorhizobium, Microvirga, Nitrospira, Nitrosospira, Rhizobacter, and Rhodanobacter) while the genera favored by the neonicotinoid treatment were dominated by Actinobacteria, including genera potentially involved in neonicotinoid degradation [e.g., Mycobacterium (Kandil et al., 2015) and Streptomyces (Guo et al., 2019)] or other pesticides degradation [e.g., Arthrobacter (Tam et al., 1987)].

\section{DISCUSSION}

Our findings indicate that habitat (soil versus phyllosphere), host species (soy versus corn), time, and their interactions are all strong drivers of bacterial composition variation in a soybean and corn agroecosystem. While this result is perhaps not surprising given that previous studies have identified these factors 
A
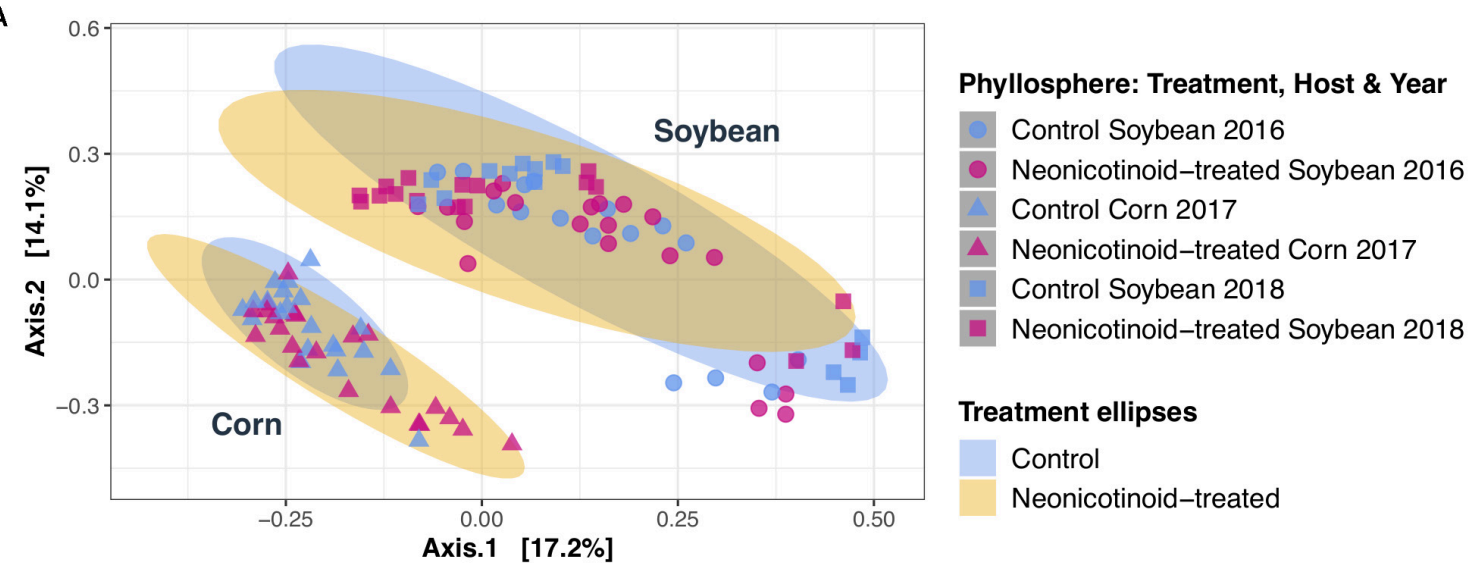

Treatment ellipses

Control

Neonicotinoid-treated
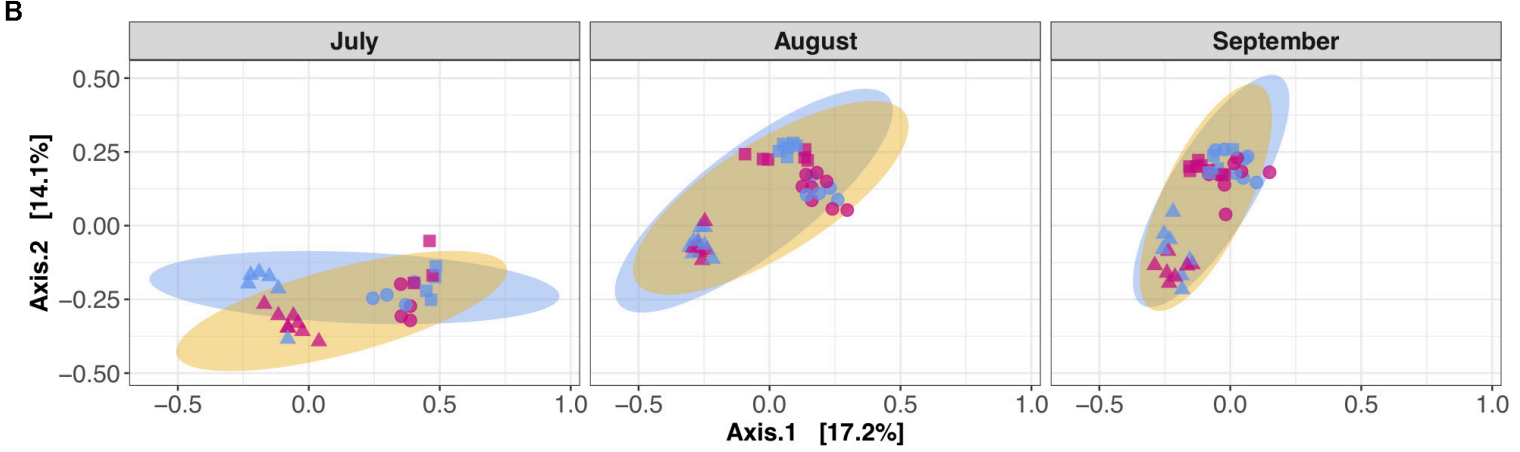

C
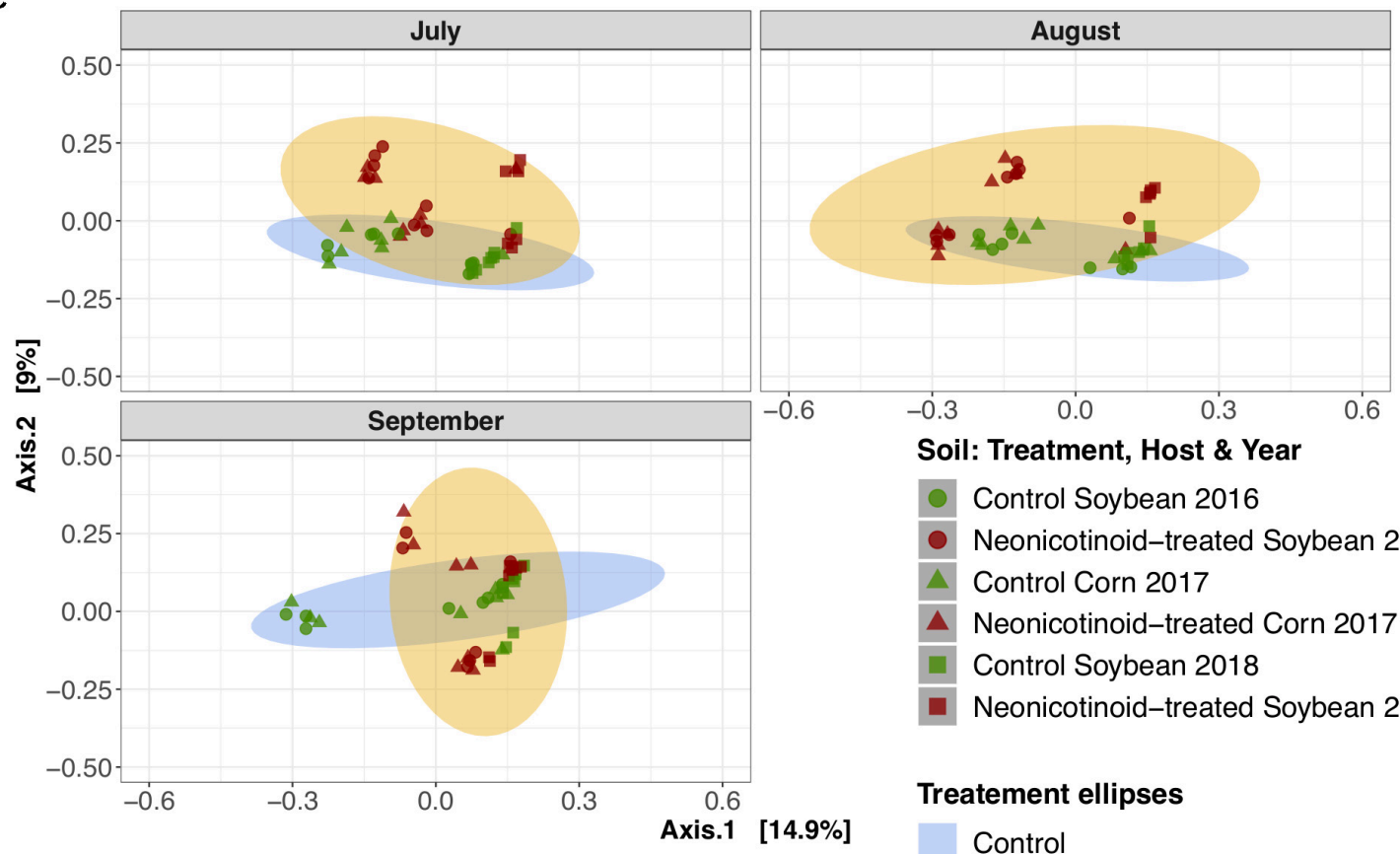

Soil: Treatment, Host \& Year

- Control Soybean 2016

- Neonicotinoid-treated Soybean 2016

Control Corn 2017

Neonicotinoid-treated Corn 2017

Control Soybean 2018

Neonicotinoid-treated Soybean 2018

Treatement ellipses

Control

Neonicotinoid-treated

FIGURE 3 | Phyllosphere and soil bacterial community composition variations in response to neonicotinoid seed treatment. Principal coordinate analysis (PCoA) on Bray-Curtis dissimilarities demonstrates the composition of phyllosphere (A,B) and soil (C) bacterial community in a 3-year soybean (2016: circles and 2018: cubes) and corn (2017: triangles) rotation in L'Acadie, Quebec, Canada. The phyllosphere bacterial community variation among control (blue points) and

neonicotinoid-treated (pink points) samples is masked by the effects of host species (A) and time (B). While in soil (C), the bacterial communities vary among control (green points) and neonicotinoid-treated (red points) samples. Ellipses are shaded based on treatment (blue for control and yellow for neonicotinoid-treated samples) and represent a 95\% confidence level. 
A
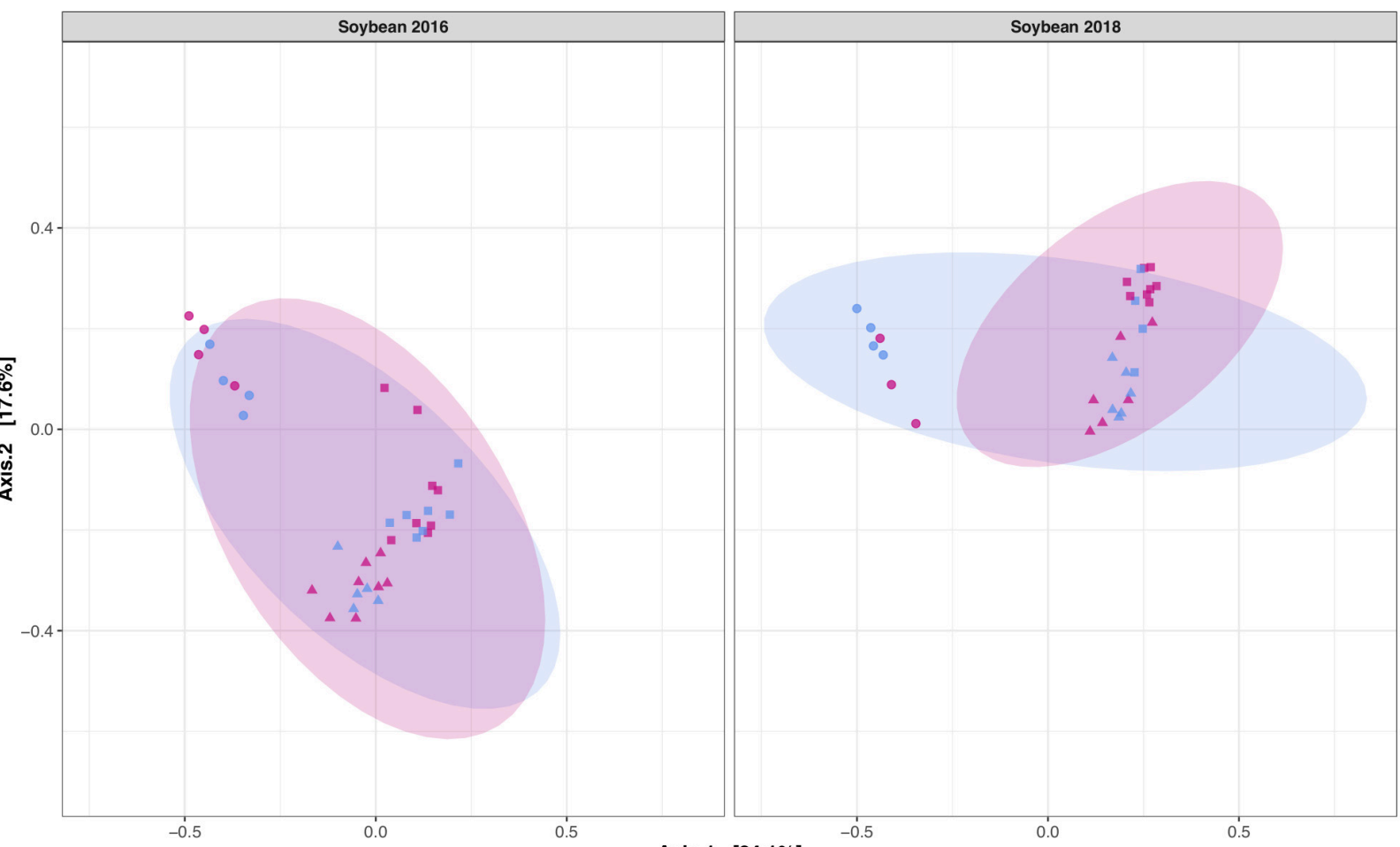

Axis.1 [24.1\%]

B

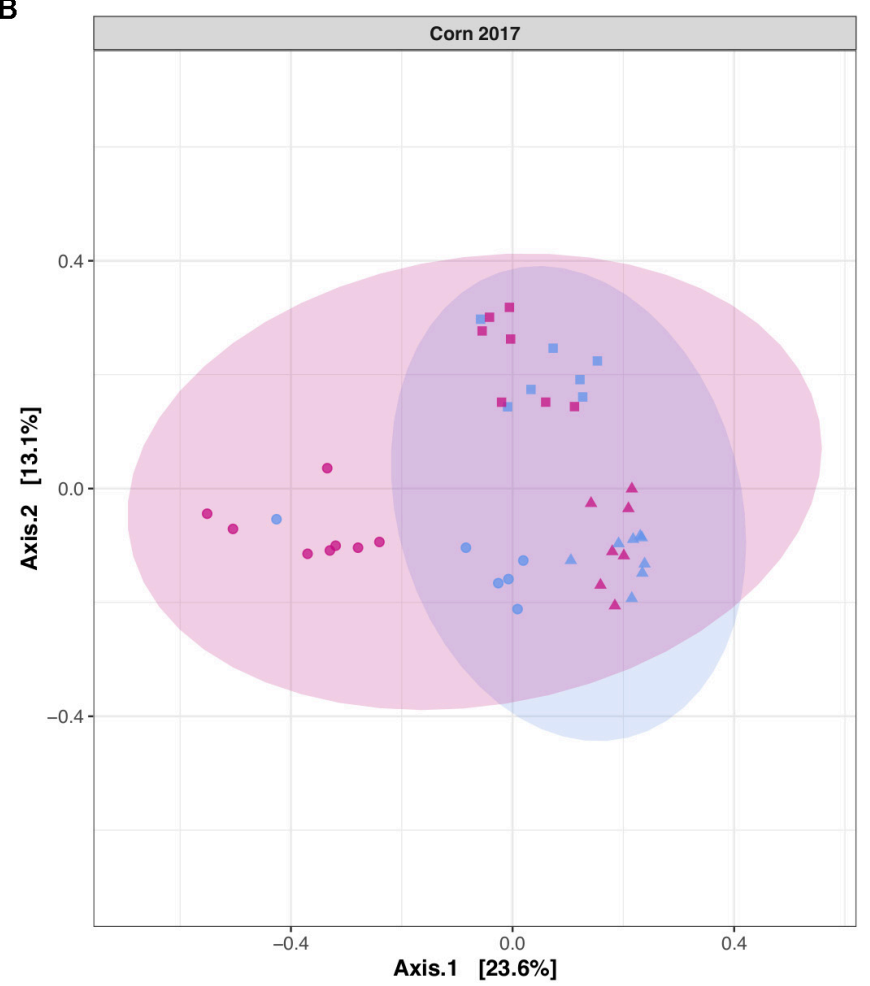

Treatment ellipses

Control

Neonicotinoid-treated
Month \& Treatement

- July - Control

- July - Neonicotinoid-treated

A August-Control

- August-Neonicotinoid-treated

September - Control

September - Neonicotinoid-treated

FIGURE 4 | Soybean and corn phyllosphere bacterial community composition variations in response to neonicotinoid seed treatment and year. Principal coordinate analysis (PCOA) on Bray-Curtis dissimilarities illustrates the phyllosphere bacterial variation individually for each host species and year of rotation in L'Acadie, Quebec, Canada: (A) soybean (left: year 2016; right: year 2018) and (B) corn (year 2017). The shapes of the points represent the month and the colors show the treatment. Ellipses are shaded based on treatment (blue for control and pink for neonicotinoid-treated samples) and represent a 95\% confidence level. 
TABLE 4 | Phyllosphere and soil bacterial phyla associated with control and neonicotinoid seed treatment.

\begin{tabular}{|c|c|c|c|}
\hline \multirow[t]{2}{*}{ Habitat } & \multirow[t]{2}{*}{ Phylum } & \multicolumn{2}{|c|}{$\begin{array}{c}\text { Number of ASVs associated } \\
\text { with treatment }\end{array}$} \\
\hline & & Control & Neonicotinoid-treated \\
\hline \multirow[t]{4}{*}{ Phyllosphere } & Actinobacteria & 1 & 3 \\
\hline & Bacteroidetes & 0 & 14 \\
\hline & Deinococcus-Thermus & 1 & 0 \\
\hline & Proteobacteria & 10 & 5 \\
\hline \multirow[t]{11}{*}{ Soil } & Acidobacteria & 11 & 0 \\
\hline & Actinobacteria & 27 & 31 \\
\hline & Bacteroidetes & 11 & 1 \\
\hline & Chloroflexi & 3 & 33 \\
\hline & Firmicutes & 2 & 0 \\
\hline & Gemmatimonadetes & 27 & 2 \\
\hline & Nitrospirae & 2 & 0 \\
\hline & Patescibacteria & 0 & 1 \\
\hline & Proteobacteria & 139 & 0 \\
\hline & Spirochetes & 1 & 0 \\
\hline & Verrucomicrobia & 3 & 0 \\
\hline
\end{tabular}

Differential expression analysis of sequence data (DESeq2) identified the bacterial phyla of the ASVs that are significantly differentially abundant (adjusted $P<0.05$ ) between control and neonicotinoid-treated samples of soybean and corn phyllosphere and soil in a 3-year rotation in L'Acadie.

as important drivers of phyllosphere (Knief et al., 2010; Kembel et al., 2014; Laforest-Lapointe et al., 2016a) and soil bacterial communities (Wieland et al., 2001; Tarlera et al., 2008; Hannula et al., 2019), our results suggest that complex interactions among these factors drive overall community composition and diversity. In particular, we have shown a role for temporal variation, alone and in interaction with habitat and host species, as an important driver of bacterial community composition variation, especially in the phyllosphere. While succession of microbial communities in the phyllosphere has been documented previously (Redford and Fierer, 2009; Wagner et al., 2016; Manching et al., 2017), here we have shown that even in a rotation of annual crops, the patterns of bacterial succession within and among years are an important driver of community structure.

We have shown that neonicotinoid seed treatments have a non-target impact on bacterial community structure and diversity in a soybean/corn agroecosystem, in particular on the taxonomic composition of soil bacterial communities over the growing season. Phyllosphere and soil bacteria exhibit different patterns of community composition, alpha diversity and temporal variation throughout the growing season and in response to neonicotinoid application. In the phyllosphere, host plant species and time are stronger drivers of bacterial community variation than neonicotinoid seed treatment; however, neonicotinoids interact with these parameters to influence the phyllosphere bacterial community composition. Overall, soil bacteria exhibited stronger changes in community composition and a significant decline in bacterial alpha diversity in response to neonicotinoid treatment, while phyllosphere bacteria responses to neonicotinoids were weaker. Our results complement previous lab-based studies of neonicotinoid effects on bacterial communities (Cai et al., 2016; Zhang et al., 2018; Yu et al., 2020), providing some of the first field-based evidence that neonicotinoids impact bacterial diversity in agroecosystems.

Overall, soil bacterial communities were more affected by neonicotinoid pesticide treatment than phyllosphere bacterial communities. Neonicotinoid effects on soil bacterial community composition and diversity varied greatly in time, with the impacts of neonicotinoid application on the soil bacterial community composition and alpha diversity most pronounced in the middle of the growing season. We suggest that this could be explained by the fact that neonicotinoids' active period is much shorter in plants (Myers and Hill, 2014; Alford and Krupke, 2017) than in soils, where they potentially persist for months or years (Goulson, 2013; Bonmatin et al., 2015). Despite the reported accumulation potential of neonicotinoids in soils over time (Wood and Goulson, 2017), we did not observe any significant inter-annual difference in bacterial diversity among years in interaction with the pesticide treatment, perhaps due to degradation or leaching of the neonicotinoids (Banerjee et al., 2008; Kurwadkar et al., 2013).

We also observed that the more homogenous the bacterial community composition is, the more it is altered by the neonicotinoid application (soil more than phyllosphere and corn phyllosphere more than soybean phyllosphere). We need further studies to determine if the homogeneity of the bacterial communities resulted in less resilience in response to perturbations or if less variability within groups allowed us to notice more changes in the communities.

In addition to community-wide responses of bacteria to the neonicotinoid treatment, numerous bacterial taxa increased or decreased in relative abundance in response to neonicotinoids. Bacterial taxa that were favored by the pesticide treatment include several genera that are known to be potentially involved in neonicotinoid degradation [e.g., Hymenobacter (Guo et al., 2020), Mycobacterium (Kandil et al., 2015), Pseudomonas (Pandey et al., 2009), and Streptomyces (Guo et al., 2019)]. In soils, there was a decline in the relative abundance of several ASVs from Proteobacteria and Gemmatimonadetes phyla and an increase in some ASVs from Chloroflexi and Actinobacteria, a result partially in accordance with a previous study that reported a decrease in the relative abundance of Gemmatimonadetes and OD1 phyla and an increase in the relative abundance of the Chloroflexi and Nitrospirae phyla in response to the neonicotinoid treatments (Yu et al., 2020).

Neonicotinoid seed treatment led to decreases in the relative abundance of several potentially beneficial soil bacteria, including the plant growth-promoting rhizobacteria (PGPR) that are capable of developing a symbiotic association with host plants [e.g., Bacillus, Bosea, Mesorhizobium, and Rhizobacter (Podile and Krishna Kishore, 2006)], nitrogen-fixing bacteria [e.g., Bradyrhizobium and Microvirga (Kumar et al., 2015)], and other bacteria involved in the nitrogen cycle [e.g., Ammoniphilus, Hyphomicrobium, Nitrospira, Nitrosospira and Rhodanobacter (Pitombo et al., 2016)]. While plant growth and yield variations in response to the pesticide application were not determined in our research, a recent study conducted 


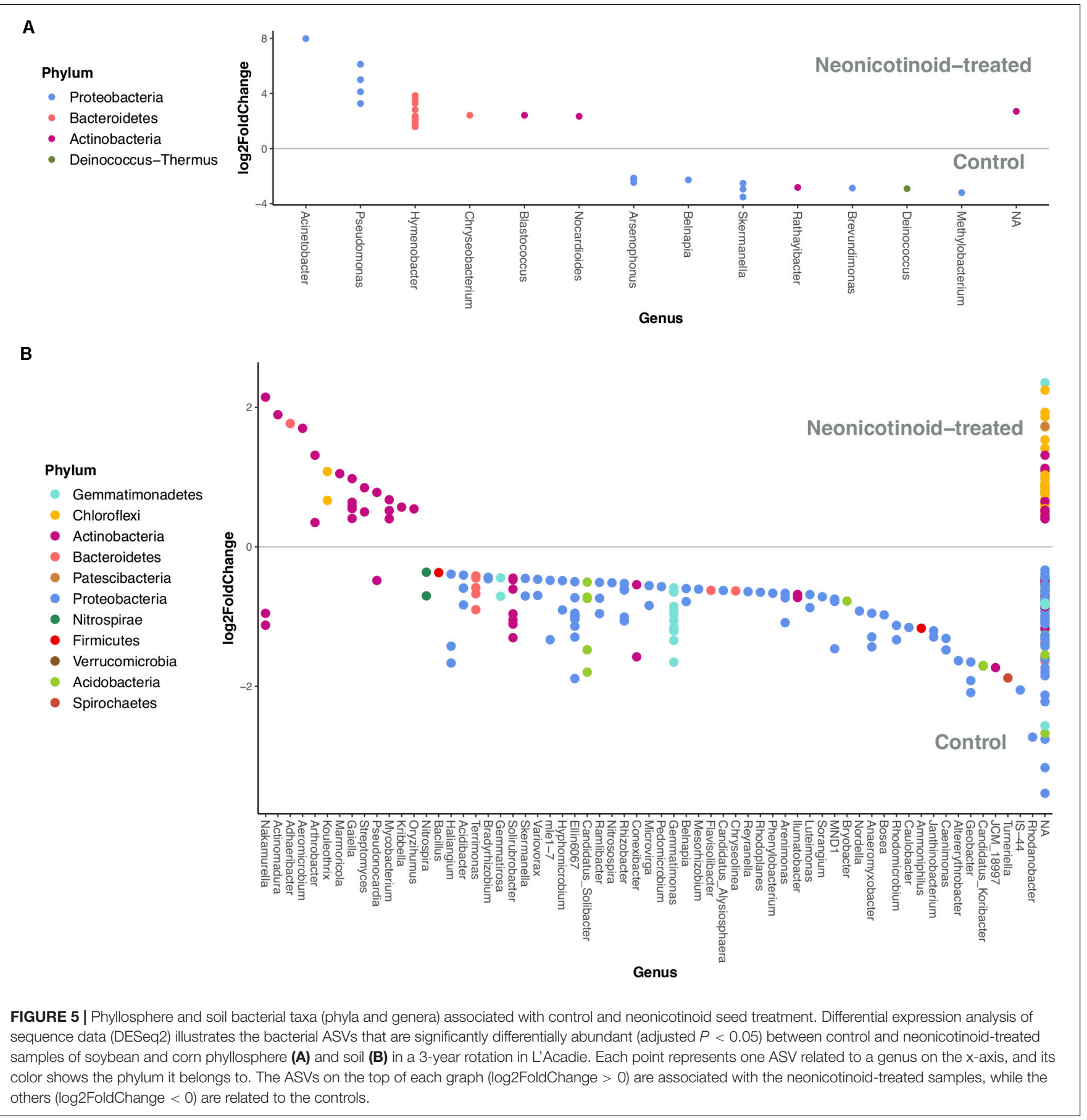

in the same bioclimatic conditions indicated no significant impact on yield in the absence of the targeted pests (Labrie et al., 2020). However, although we did not measure the effects of neonicotinoid treatments on ecosystem processes such as nitrification, our results suggest a potential mechanism for the negative effects of neonicotinoids on nitrification that have been observed in previous studies (Filimon et al., 2015; Zhang et al., 2018).

Given that invertebrates are the main target of neonicotinoids, we suggest that the effects of this pesticide on bacterial communities could be related to the trophic interactions between bacteria and the invertebrates (e.g., free-living nematodes and microarthropods) affected by neonicotinoids. This insecticide may indirectly alter the bacterial community composition by affecting the top-down regulation of these communities through reducing the higher trophic levels that feed on bacteria (Staley et al., 2015; Thakur and Geisen, 2019). Future research to evaluate the effects of neonicotinoids on these eukaryotic microbial communities, the trans-kingdom and trophic interactions between them and bacterial communities, and especially the 
prey-predator dynamics, as well as gene expression and functional variations of microbial communities, will improve our understanding of the mechanisms driving the microbial community variations in response to the pesticide application.

\section{CONCLUSION}

To date, there have been few studies that have evaluated the impacts of neonicotinoid seed treatments on phyllosphere and soil bacterial communities. To our knowledge, this study is the first with an experimental design that represents real farming conditions in a crop rotation. Despite the fact that neonicotinoids target invertebrates, we observed their nontarget impacts on bacterial communities of the phyllosphere and soil, especially the beneficial bacteria that are crucial for plant growth and health and soil fertility and quality. Future studies to identify the genomic and physiological features associated with tolerance of neonicotinoids will be required to understand the mechanistic reasons for these associations. Investigating the biological and trophic interactions among bacteria and other micro- and macro-organisms that are affected by pesticides will help us to better understand the non-target effects of pesticides on microbial diversity and how to control them with better agricultural practices.

\section{DATA AVAILABILITY STATEMENT}

We have deposited the raw sequences at the NCBI Sequence Read Archive (SRA accession number PRJNA662376). Scripts to perform the analyses of the current study are available in the following GitHub repository: https:/github.com/memoll/ acadie_16s.

\section{AUTHOR CONTRIBUTIONS}

MP, BM, and SK conceived and designed the study. BM and SK obtained the funding. MP collected and analyzed the data and wrote the manuscript. All authors critically reviewed and edited the manuscript.

\section{FUNDING}

This research was funded by Agriculture and Agri-Food Canada (BM), the Natural Sciences and Engineering Research Council

\section{REFERENCES}

Acinas, S. G., Sarma-Rupavtarm, R., Klepac-Ceraj, V., and Polz, M. F. (2005). PCRinduced sequence artifacts and bias: insights from comparison of two 16S rRNA clone libraries constructed from the same sample. Appl. Environ. Microbiol. 71, 8966-8969. doi: 10.1128/AEM.71.12.8966-8969.2005

Ahemad, M., and Khan, M. S. (2012). Ecological assessment of biotoxicity of pesticides towards plant growth promoting activities of pea (Pisum sativum)Specific Rhizobium sp. Strain MRP1. J. Sci. Food Agric. 24, 334-343. of Canada Discovery Grants program (SK) and the Canada Research Chair (SK). It was also enabled in part by support provided by Compute Canada and Calcul Quebec.

\section{ACKNOWLEDGMENTS}

We are grateful to Michel Fortin, Éléonore Tremblay, PierreYves Véronneau, Katherine Bisaillon, and other colleagues in AAFC for assistance in crop cultivation and sample collection, processing and sequencing. We also thank Gaston Mercier (AAFC) for performing soil physicochemical analysis. Finally, we thank Étienne Lord (AAFC) for his help in data processing, and Geneviève Labrie (CRAM) and Annie-Ève Gagnon (AAFC) for their valuable scientific advice and suggestions. This manuscript has been released as a pre-print at ResearchSquare (Parizadeh et al., 2020).

\section{SUPPLEMENTARY MATERIAL}

The Supplementary Material for this article can be found online at: https://www.frontiersin.org/articles/10.3389/fmicb. 2020.619827/full\#supplementary-material

Supplementary Table 1 | Soil physicochemical properties. For each plot, physicochemical properties of soil were measured every year, twice (2016 and 2017) or three times (2018) during the growing seasons.

Supplementary Table 2 | Correlation between bacterial families relative abundances and their habitats and host species. Envfit analysis of correlations between bacterial families of soybean and corn phyllosphere and soil with an average relative abundance of more than 0.01 and the axes of PCoA ordination (on Bray-Curtis dissimilarities). $(\checkmark)$ and $(-$ ), respectively, show whether the bacterial family is significantly correlated with the soybean or corn phyllosphere or soil or not. Significance levels for each variable are given by: ${ }^{* * *} P<0.001$; ${ }^{* *} P<0.01$; ${ }^{*} P<0.05$; NS: $P \geq 0.05$.

Supplementary Table $\mathbf{3}$ | Significantly differentially bacterial ASVs of phyllosphere associated with control and neonicotinoid seed treatment. Differential expression analysis on sequence data (DESeq2) detects the bacterial ASVs that are significantly differentially abundant (adjusted $P<0.05$ ) between soybean and corn phyllosphere control and neonicotinoid-treated samples in a 3-year rotation in L'Acadie. The ASVs with a positive log2FoldChange are associated with the neonicotinoid-treated samples, while the ones with a negative log2FoldChange are related to the controls.

Supplementary Table 4 | Significantly differentially soil bacterial ASVs associated with control and neonicotinoid seed treatment. Differential expression analysis on sequence data (DESeq2) identifies the ASVs that are significantly differentially abundant (adjusted $P<0.05$ ) between the control and neonicotinoid-treated samples of soybean and corn soil bacteria in a 3-year rotation in L'Acadie. The ASVs favored by neonicotinoid-treated samples have a positive log2FoldChange, while the ASVs associated with control have a negative log2FoldChange. 
Banerjee, K., Patil, S. H., Dasgupta, S., Oulkar, D. P., and Adsule, P. G. (2008). Sorption of thiamethoxam in three Indian soils. J. Environ. Sci. Health B 43, 151-156. doi: 10.1080/03601230701795130

Bonmatin, J.-M., Giorio, C., Girolami, V., Goulson, D., Kreutzweiser, D. P., Krupke, C., et al. (2015). Environmental fate and exposure; neonicotinoids and fipronil. Environ. Sci. Pollut. Res. Int. 22, 35-67. doi: 10.1007/s11356-0143332-7

Bonmatin, J. M., Marchand, P. A., Charvet, R., Moineau, I., Bengsch, E. R., and Colin, M. E. (2005). Quantification of imidacloprid uptake in maize crops. J. Agric. Food Chem. 53, 5336-5341. doi: 10.1021/jf0479362

Bray, J. R., and Curtis, J. T. (1957). An ordination of the upland forest communities of southern wisconsin. Ecol. Monogr. 27, 325-349. doi: 10.2307/194 2268

Cai, Z., Ma, J., Wang, J., Cai, J., Yang, G., and Zhao, X. (2016). Impact of the novel neonicotinoid insecticide Paichongding on bacterial communities in yellow loam and Huangshi soils. Environ. Sci. Pollut. Res. Int. 23, 5134-5142. doi: 10.1007/s11356-015-5733-7

Callahan, B. J., McMurdie, P. J., Rosen, M. J., Han, A. W., Johnson, A. J. A., and Holmes, S. P. (2016). DADA2: high-resolution sample inference from Illumina amplicon data. Nat. Methods 13, 581-583. doi: 10.1038/nmeth. 3869

Chelius, M. K., and Triplett, E. W. (2001). The diversity of archaea and bacteria in association with the roots of Zea mays L. Microb. Ecol. 41, 252-263. doi: $10.1007 / \mathrm{s} 002480000087$

Clairmont, L. K., Stevens, K. J., and Slawson, R. M. (2019). Site-specific differences in microbial community structure and function within the rhizosphere and rhizoplane of wetland plants is plant species dependent. Rhizosphere 9, 56-68. doi: 10.1016/j.rhisph.2018.11.006

Cox, W. J., and Cherney, J. H. (2011). Location, variety, and seeding rate interactions with soybean seed-applied insecticide/fungicides. Agron. J. 103, 1366-1371. doi: 10.2134/agronj2011.0129

Cycoń, M., Markowicz, A., Borymski, S., Wójcik, M., and Piotrowska-Seget, Z. (2013). Imidacloprid induces changes in the structure, genetic diversity and catabolic activity of soil microbial communities. J. Environ. Manage. 131, 55-65. doi: 10.1016/j.jenvman.2013.09.041

Cycoń, M., and Piotrowska-Seget, Z. (2015). Biochemical and microbial soil functioning after application of the insecticide imidacloprid. J. Environ. Sci. 27, 147-158. doi: 10.1016/j.jes.2014.05.034

Davis, N. M., Proctor, D. M., Holmes, S. P., Relman, D. A., and Callahan, B. J. (2018). Simple statistical identification and removal of contaminant sequences in marker-gene and metagenomics data. Microbiome 6:226. doi: 10.1186/ s40168-018-0605-2

Doran, J. W., and Zeiss, M. R. (2000). Soil health and sustainability: managing the biotic component of soil quality. Appl. Soil Ecol. 15, 3-11. doi: 10.1016/S09291393(00)00067-6

Douglas, M. R., and Tooker, J. F. (2015). Large-scale deployment of seed treatments has driven rapid increase in use of neonicotinoid insecticides and preemptive pest management in US field crops. Environ. Sci. Technol. 49, 5088-5097. doi: $10.1021 /$ es506141g

Elbert, A., Haas, M., Springer, B., Thielert, W., and Nauen, R. (2008). Applied aspects of neonicotinoid uses in crop protection. Pest Manag. Sci. 64, 10991105. doi: $10.1002 / \mathrm{ps} .1616$

Fierer, N., Nemergut, D., Knight, R., and Craine, J. M. (2010). Changes through time: integrating microorganisms into the study of succession. Res. Microbiol. 161, 635-642. doi: 10.1016/j.resmic.2010.06.002

Filimon, M. N., Voia, S. O., Popescu, R., Dumitrescu, G., Ciochina, L. P., Mituletu, M., et al. (2015). The effect of some insecticides on soil microorganisms based on enzymatic and bacteriological analyses. Rom. Biotechnol. Lett. 20, 10439-10447.

Fox, J. E., Gulledge, J., Engelhaupt, E., Burow, M. E., and McLachlan, J. A. (2007). Pesticides reduce symbiotic efficiency of nitrogen-fixing rhizobia and host plants. Proc. Natl. Acad. Sci. U.S.A. 104, 10282-10287. doi: 10.1073/pnas. 0611710104

Gagic, V., Kleijn, D., Báldi, A., Boros, G., Jørgensen, H. B., Elek, Z., et al. (2017). Combined effects of agrochemicals and ecosystem services on crop yield across Europe. Ecol. Lett. 20, 1427-1436. doi: 10.1111/ele.12850

Garbeva, P., van Veen, J. A., and van Elsas, J. D. (2004). Microbial diversity in soil: selection of microbial populations by plant and soil type and implications for disease suppressiveness. Annu. Rev. Phytopathol. 42, 243-270. doi: 10.1146/ annurev.phyto.42.012604.135455

Girolami, V., Mazzon, L., Squartini, A., Mori, N., Marzaro, M., Di Bernardo, A., et al. (2009). Translocation of neonicotinoid insecticides from coated seeds to seedling guttation drops: a novel way of intoxication for bees. J. Econ. Entomol. 102, 1808-1815. doi: 10.1603/029.102.0511

Goulson, D. (2013). Review: an overview of the environmental risks posed by neonicotinoid insecticides. J. Appl. Ecol. 50, 977-987. doi: 10.1111/1365-2664. 12111

Guo, L., Dai, Z., Guo, J., Yang, W., Ge, F., and Dai, Y. (2020). Oligotrophic bacterium Hymenobacter latericoloratus CGMCC 16346 degrades the neonicotinoid imidacloprid in surface water. AMB Express 10:7. doi: 10.1186/s13568-019-0942-y

Guo, L., Fang, W.-W., Guo, L.-L., Yao, C.-F., Zhao, Y.-X., Ge, F., et al. (2019). Biodegradation of the neonicotinoid insecticide acetamiprid by actinomycetes Streptomyces canus CGMCC 13662 and characterization of the novel nitrile hydratase involved. J. Agric. Food Chem. 67, 5922-5931. doi: 10.1021/acs.jafc. 8 b06513

Hannula, S. E., Kielak, A. M., Steinauer, K., Huberty, M., Jongen, R., De Long, J. R., et al. (2019). Time after time: temporal variation in the effects of grass and forb species on soil bacterial and fungal communities. MBio 10:e2635-19. doi: 10.1128/mBio.02635-19

Hochberg, Y., and Benjamini, Y. (1990). More powerful procedures for multiple significance testing. Stat. Med. 9, 811-818. doi: 10.1002/sim.4780090710

Holm, S. (1979). A simple sequentially rejective multiple test procedure. Scand. Stat. Theory Appl. 6, 65-70.

Hussain, S., Siddique, T., Saleem, M., Arshad, M., and Khalid, A. (2009). Chapter 5 impact of pesticides on soil microbial diversity, enzymes, and biochemical reactions. Adv. Agron. 102, 159-200. doi: 10.1016/S0065-2113(09)01005-0

Itoh, H., Navarro, R., Takeshita, K., Tago, K., Hayatsu, M., Hori, T., et al. (2014). Bacterial population succession and adaptation affected by insecticide application and soil spraying history. Front. Microbiol. 5:457. doi: 10.3389/ fmicb.2014.00457

Iwasa, T., Motoyama, N., Ambrose, J. T., and Roe, R. M. (2004). Mechanism for the differential toxicity of neonicotinoid insecticides in the honey bee, Apis mellifera. Crop. Prot. 23, 371-378. doi: 10.1016/j.cropro.2003.08.018

Kagabu, S. (1996). Studies on the synthesis and insecticidal activity of neonicotinoid compounds. J. Pestic. Sci. 21, 231-239. doi: 10.1584/jpestics. 21.231

Kandil, M. M., Trigo, C., Koskinen, W. C., and Sadowsky, M. J. (2015). Isolation and characterization of a novel imidacloprid-degrading Mycobacterium sp. strain mk6 from an egyptian Soil. J. Agric. Food Chem. 63, 4721-4727. doi: 10.1021/acs.jafc.5b00754

Kembel, S. W., O'Connor, T. K., Arnold, H. K., Hubbell, S. P., Wright, S. J., and Green, J. L. (2014). Relationships between phyllosphere bacterial communities and plant functional traits in a neotropical forest. Proc. Natl. Acad. Sci. U.S.A. 111, 13715-13720. doi: 10.1073/pnas.1216057111

Kim, M.-S., Bae, J.-W., and Park, E.-J. (2018). Geographic and host-associated variations in bacterial communities on the floret surfaces of field-grown broccoli. Appl. Environ. Microbiol. 84:e2837-17. doi: 10.1128/AEM.02837-17

Knief, C., Ramette, A., Frances, L., Alonso-Blanco, C., and Vorholt, J. A. (2010). Site and plant species are important determinants of the Methylobacterium community composition in the plant phyllosphere. ISME J. 4, 719-728. doi: 10.1038/ismej.2010.9

Kumar, A., Bahadur, I., Maurya, B. R., Raghuwanshi, R., Meena, V. S., Singh, D. K., et al. (2015). Does a plant growth-promoting rhizobacteria enhance agricultural sustainability. J. Pure Appl. Microbiol. 9, 715-724.

Kurwadkar, S. T., Dewinne, D., Wheat, R., McGahan, D. G., and Mitchell, F. L. (2013). Time dependent sorption behavior of dinotefuran, imidacloprid and thiamethoxam. J. Environ. Sci. Health B 48, 237-242. doi: 10.1080/03601234. 2013.742412

Labrie, G., Gagnon, A. -È, Vanasse, A., Latraverse, A., and Tremblay, G. (2020). Impacts of neonicotinoid seed treatments on soil-dwelling pest populations and agronomic parameters in corn and soybean in Quebec (Canada). PLoS One 15:e0229136. doi: 10.1371/journal.pone.0229136

Laforest-Lapointe, I., Messier, C., and Kembel, S. W. (2016a). Host species identity, site and time drive temperate tree phyllosphere bacterial community structure. Microbiome 4:27. doi: 10.1186/s40168-016-0174-171 
Laforest-Lapointe, I., Messier, C., and Kembel, S. W. (2016b). Tree phyllosphere bacterial communities: exploring the magnitude of intra- and inter-individual variation among host species. PeerJ 4:e2367. doi: 10.7717/peerj.2367

Lo, C. C. (2010). Effect of pesticides on soil microbial community. J. Environ. Sci. Health B 45, 348-359. doi: 10.1080/10934520903467873

Love, M. I., Huber, W., and Anders, S. (2014). Moderated estimation of fold change and dispersion for RNA-seq data with DESeq2. Genome Biol. 15:550. doi: 10.1186/s13059-014-0550-8

Manching, H. C., Carlson, K., Kosowsky, S., Smitherman, C. T., and Stapleton, A. E. (2017). Maize phyllosphere microbial community niche development across stages of host leaf growth. F1000Res. 6:1698. doi: 10.12688/f1000research. 12490.3

Moulas, C., Petsoulas, C., Rousidou, K., Perruchon, C., Karas, P., and Karpouzas, D. G. (2013). Effects of systemic pesticides imidacloprid and metalaxyl on the phyllosphere of pepper plants. Biomed Res. Int. 2013:969750. doi: 10.1155/2013/ 969750

Myers, C., and Hill, E. (2014). Benefits of Neonicotinoid Seed Treatments to Soybean Production. Washington, DC: Memorandum to United States Environmental Protection Agency.

Pandey, G., Dorrian, S. J., Russell, R. J., and Oakeshott, J. G. (2009). Biotransformation of the neonicotinoid insecticides imidacloprid and thiamethoxam by Pseudomonas sp. 1G. Biochem. Biophys. Res. Commun. 380, 710-714. doi: 10.1016/j.bbrc.2009.01.156

Parizadeh, M., Mimee, B., and Kembel, S. W. (2020). Effects of Neonicotinoid Seed Treatments on Phyllosphere and Soil Bacterial Communities Over Time. Durham, NC: ResearchSquare doi: 10.21203/rs.3.rs-76081/v1

Penn, H. J., and Dale, A. M. (2017). Imidacloprid seed treatments affect individual ant behavior and community structure but not egg predation, pest abundance or soybean yield. Pest Manag. Sci. 73, 1625-1632. doi: 10.1002/ps.4499

Pisa, L. W., Amaral-Rogers, V., Belzunces, L. P., Bonmatin, J. M., Downs, C. A., Goulson, D., et al. (2015). Effects of neonicotinoids and fipronil on non-target invertebrates. Environ. Sci. Pollut. Res. Int. 22, 68-102. doi: 10.1007/s11356014-3471-x

Pitombo, L. M., do Carmo, J. B., de Hollander, M., Rossetto, R., López, M. V., Cantarella, H., et al. (2016). Exploring soil microbial 16S rRNA sequence data to increase carbon yield and nitrogen efficiency of a bioenergy crop. GCB Bioenergy 8, 867-879. doi: 10.1111/gcbb.12284

Podile, A. R., and Krishna Kishore, G. (2006). "Plant growth-promoting rhizobacteria," in Plant-Associated Bacteria, ed. S. S. Gnanamanickam (Berlin: Springer), 195-230. doi: 10.1007/1-4020-4538-7_6

Quast, C., Pruesse, E., Yilmaz, P., Gerken, J., Schweer, T., Yarza, P., et al. (2013). The SILVA ribosomal RNA gene database project: improved data processing and web-based tools. Nucleic Acids Res. 41, D590-D596. doi: 10.1093/nar/gks1219

R Core Team (2019). R: A Language and Environment for Statistical Computing. Vienna: R Foundation for Statistical Computing.

Redford, A. J., Bowers, R. M., Knight, R., Linhart, Y., and Fierer, N. (2010). The ecology of the phyllosphere: geographic and phylogenetic variability in the distribution of bacteria on tree leaves. Environ. Microbiol. 12, 2885-2893. doi: $10.1111 / j .1462-2920.2010 .02258 . x$

Redford, A. J., and Fierer, N. (2009). Bacterial succession on the leaf surface: a novel system for studying successional dynamics. Microb. Ecol. 58, 189-198. doi: 10.1007/s00248-009-9495-y

Reisig, D. D., Herbert, D. A., and Malone, S. (2012). Impact of neonicotinoid seed treatments on thrips (Thysanoptera: Thripidae) and soybean yield in Virginia and North Carolina. J. Econ. Entomol. 105, 884-889. doi: 10.1603/ec11429

Rodríguez-Valdecantos, G., Manzano, M., Sánchez, R., Urbina, F., Hengst, M. B., Lardies, M. A., et al. (2017). Early successional patterns of bacterial communities in soil microcosms reveal changes in bacterial community composition and network architecture, depending on the successional condition. Appl. Soil Ecol. 120, 44-54. doi: 10.1016/j.apsoil.2017.07.015

Samaritani, E., Mitchell, E. A. D., Rich, J., Shrestha, J., Fournier, B., and Frey, B. (2017). Soil bacterial communities and ecosystem functioning change more strongly with season than habitat in a restoredfloodplain. Appl. Soil Ecol. 112, 71-78. doi: 10.1016/j.apsoil.2016.12.010

Samson-Robert, O., Labrie, G., Chagnon, M., and Fournier, V. (2014). Neonicotinoid-contaminated puddles of water represent a risk of intoxication for honey bees. PLoS One 9:e108443. doi: 10.1371/journal.pone.0108443
Samson-Robert, O., Labrie, G., Chagnon, M., and Fournier, V. (2017). Planting of neonicotinoid-coated corn raises honey bee mortality and sets back colony development. PeerJ 5:e3670. doi: 10.7717/peerj.3670

Sanchez-Bayo, F., and Goka, K. (2014). Pesticide residues and bees-a risk assessment. PLoS One 9:e94482. doi: 10.1371/journal.pone.0094482

Schimel, J., Balser, T. C., and Wallenstein, M. (2007). Microbial stress-response physiology and its implications for ecosystem function. Ecology 88, 1386-1394. doi: 10.1890/06-0219

Singh, J., and Singh, D. K. (2006). Ammonium, nitrate and nitrite nitrogen and nitrate reductase enzyme activity in groundnut (Arachis hypogaea L.) fields after diazinon, imidacloprid and lindane treatments. J. Environ. Sci. Health B 41, 1305-1318. doi: 10.1080/03601230600963938

Staley, Z. R., Harwood, V. J., and Rohr, J. R. (2015). A synthesis of the effects of pesticides on microbial persistence in aquatic ecosystems. Crit. Rev. Toxicol. 45, 813-836. doi: 10.3109/10408444.2015.1065471

Sugiyama, A., Ueda, Y., Zushi, T., Takase, H., and Yazaki, K. (2014). Changes in the bacterial community of soybean rhizospheres during growth in the field. PLoS One 9:e100709. doi: 10.1371/journal.pone.0100709

Sur, R., and Stork, A. (2003). Uptake, translocation and metabolism of imidacloprid in plants. Bull. Insectol. 56, 35-40.

Tam, A. C., Behki, R. M., and Khan, S. U. (1987). Isolation and characterization of an s-ethyl-N, N-dipropylthiocarbamate-degrading Arthrobacter strain and evidence for plasmid-associated s-ethyl-N, N-dipropylthiocarbamate degradation. Appl. Environ. Microbiol. 53, 1088-1093. doi: 10.1128/aem.53.5. 1088-1093.1987

Tarlera, S., Jangid, K., Ivester, A. H., Whitman, W. B., and Williams, M. A. (2008). Microbial community succession and bacterial diversity in soils during 77,000 years of ecosystem development. FEMS Microbiol. Ecol. 64, 129-140. doi: 10. 1111/j.1574-6941.2008.00444.x

Thakur, M. P., and Geisen, S. (2019). Trophic regulations of the soil microbiome. Trends Microbiol. 27, 771-780. doi: 10.1016/j.tim.2019.04.008

Tomizawa, M., and Casida, J. E. (2003). Selective toxicity of neonicotinoids attributable to specificity of insect and mammalian nicotinic receptors. Annu. Rev. Entomol. 48, 339-364. doi: 10.1146/annurev.ento.48.091801.112731

Tomizawa, M., and Casida, J. E. (2005). Neonicotinoid insecticide toxicology: mechanisms of selective action. Annu. Rev. Pharmacol. Toxicol. 45, 247-268. doi: 10.1146/annurev.pharmtox.45.120403.095930

Tomizawa, M., Latli, B., and Casida, J. E. (1999). "Structure and function of insect nicotinic acetylcholine receptors studied with nicotinoid insecticide affinity probes," in Nicotinoid Insecticides and the Nicotinic Acetylcholine Receptor, eds I. Yamamoto and J. E. Casida (Tokyo: Springer), 271-292. doi: 10.1007/978-4431-67933-2_13

Vorholt, J. A. (2012). Microbial life in the phyllosphere. Nat. Rev. Microbiol. 10, 828-840. doi: 10.1038/nrmicro2910

Wagner, M. R., Lundberg, D. S., Del Rio, T. G., Tringe, S. G., Dangl, J. L., and Mitchell-Olds, T. (2016). Host genotype and age shape the leaf and root microbiomes of a wild perennial plant. Nat. Commun. 7:12151. doi: 10.1038/ ncomms 12151

Whipps, J. M., Hand, P., Pink, D., and Bending, G. D. (2008). Phyllosphere microbiology with special reference to diversity and plant genotype. J. Appl. Microbiol. 105, 1744-1755. doi: 10.1111/j.1365-2672.2008.03906.x

Wieland, G., Neumann, R., and Backhaus, H. (2001). Variation of microbial communities in soil, rhizosphere, and rhizoplane in response to crop species, soil type, and crop development. Appl. Environ. Microbiol. 67, 5849-5854. doi: 10.1128/AEM.67.12.5849-5854.2001

Wilcoxon, F. (1945). Individual comparisons by ranking methods. Biometr. Bull. 1, 80-83. doi: $10.2307 / 3001968$

Wood, T. J., and Goulson, D. (2017). The environmental risks of neonicotinoid pesticides: a review of the evidence post 2013. Environ. Sci. Pollut. Res. 24, 17285-17325. doi: 10.1007/s11356-017-9240-x

Yilmaz, P., Parfrey, L. W., Yarza, P., Gerken, J., Pruesse, E., Quast, C., et al. (2014). The SILVA and "All-species living tree project (LTP)" taxonomic frameworks. Nucleic Acids Res. 42, D643-D648. doi: 10.1093/nar/gkt1209

Yu, B., Chen, Z., Lu, X., Huang, Y., Zhou, Y., Zhang, Q., et al. (2020). Effects on soil microbial community after exposure to neonicotinoid insecticides thiamethoxam and dinotefuran. Sci. Total Environ. 725:138328. doi: 10.1016/ j.scitotenv.2020.138328 
Zhang, B., Bai, Z., Hoefel, D., Tang, L., Wang, X., Li, B., et al. (2009). The impacts of cypermethrin pesticide application on the non-target microbial community of the pepper plant phyllosphere. Sci. Total Environ. 407, 1915-1922. doi: 10. 1016/j.scitotenv.2008.11.049

Zhang, B., Zhang, H., Jin, B., Tang, L., Yang, J., Li, B., et al. (2008). Effect of cypermethrin insecticide on the microbial community in cucumber phyllosphere. J. Environ. Sci. 20, $1356-1362$.

Zhang, P., Ren, C., Sun, H., and Min, L. (2018). Sorption, desorption and degradation of neonicotinoids in four agricultural soils and their effects on soil microorganisms. Sci. Total Environ. 615, 59-69. doi: 10.1016/j.scitotenv.2017. 09.097

Zhang, P., Zhang, X., Zhao, Y., Wei, Y., Mu, W., and Liu, F. (2016). Effects of imidacloprid and clothianidin seed treatments on wheat aphids and their natural enemies on winter wheat. Pest Manag. Sci. 72, 1141-1149. doi: 10.1002/ ps. 4090

Conflict of Interest: The authors declare that the research was conducted in the absence of any commercial or financial relationships that could be construed as a potential conflict of interest.

Copyright (๑) 2021 Her Majesty the Queen in Right of Canada, as represented by Agriculture and Agri-Food Canada (AAFC). This is an open-access article distributed under the terms of the Creative Commons Attribution License (CC BY). The use, distribution or reproduction in other forums is permitted, provided the original author(s) and the copyright owner(s) are credited and that the original publication in this journal is cited, in accordance with accepted academic practice. No use, distribution or reproduction is permitted which does not comply with these terms. 